\title{
Evaluation of Spatial and Temporal Performances of ERA-Interim Precipitation and Temperature in Mainland China ${ }^{\mathscr{O}}$
}

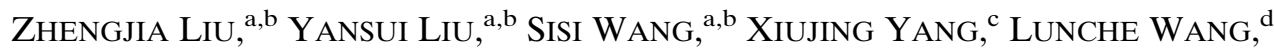 \\ Muhammad Hasan Ali Baig, ${ }^{\mathrm{e}}$ Wenfeng Chi, ${ }^{\mathrm{f}}$ And ZhaOsheng Wang ${ }^{\mathrm{g}}$ \\ ${ }^{a}$ Institute of Geographic Sciences and Natural Resources Research, Chinese Academy of Sciences, Beijing, China \\ ${ }^{\mathrm{b}}$ College of Resources and Environment, University of Chinese Academy of Sciences, Beijing, China \\ ${ }^{\mathrm{c}}$ Key Laboratory of Regional Climate-Environment for Temperate East Asia, Institute \\ of Atmospheric Physics, Chinese Academy of Sciences, Beijing, China \\ ${ }^{\mathrm{d}}$ School of Earth Sciences, China University of Geosciences, Wuhan, China \\ ${ }^{\mathrm{e}}$ Institute of Geo-Information and Earth Observation, Arid Agriculture University Rawalpindi, Rawalpindi, Pakistan \\ ${ }^{\mathrm{f}}$ Resources and Environment Economy College, Inner Mongolia University of Finance and Economics, Hohhot, China \\ ${ }^{\mathrm{g}}$ State Key Laboratory of Loess and Quaternary Geology, Institute of Earth Environment, \\ Chinese Academy of Sciences, Xi'an, China
}

(Manuscript received 3 April 2017, in final form 2 December 2017)

\begin{abstract}
ERA-Interim has been widely considered as a valid proxy for observations at global and regional scales. However, the verifications of ERA-Interim precipitation and temperature in mainland China have been rarely conducted, especially in the spatial and long-term performances. Therefore, in this study, we employed the interpolated ground station (STA) data to evaluate the spatial and temporal patterns and trends of ERAInterim precipitation and temperature during 1980-2012. The results showed that relatively weaker performances were observed in ERA-Interim precipitation, with the skill score ( $\mathrm{S}$ index) ranging from 0.41 to 0.50. Interannual ERA-Interim precipitation presented comparable trends with STA precipitation at the annual and seasonal scales. Spatial patterns of empirical orthogonal function (EOF) modes and corresponding principal components were evidently different between annual ERA-Interim and STA precipitation. For temperature, annual and seasonal patterns of ERA-Interim data were in good consistency with those of STA over China with the S index ranging from 0.59 to 0.70 . Yet interannual STA temperature recorded stronger warming trends (from $0.37 \mathrm{~K} \mathrm{decade}^{-1}$ of wintertime to $0.53 \mathrm{~K} \mathrm{decade}^{-1}$ of springtime) at the annual and seasonal scales compared to corresponding periods for ERA-Interim temperature (from $0.03 \mathrm{~K} \mathrm{decade}^{-1}$ of wintertime to $0.25 \mathrm{~K} \mathrm{decade}^{-1}$ of summertime). Overall, ERA-Interim precipitation and temperature had good agreement with STA data in east China with lower elevation $(<1000 \mathrm{~m}$ above sea level), but good agreements were not observed in west China with higher elevation. The findings suggest that caution should be paid when using ERA-Interim precipitation and temperature in areas with complex orography.
\end{abstract}

\section{Introduction}

Precipitation and temperature play important roles in the climatic system, which is widely used for explaining the response of the terrestrial ecosystems to climate change and regional climatic modeling (Colucci and Guglielmin 2015; Decker et al. 2012; Jiang et al. 2017; Liu et al. 2005, 2015; Oberhänsli et al. 2011; Vergni and Todisco 2011).

Supplemental information related to this paper is available at the Journals Online website: https://doi.org/10.1175/JCLI-D-170212.s1.

Corresponding author: Yansui Liu, liuys@igsnrr.ac.cn
Traditionally, observations of precipitation and temperature are based on ground meteorological stations (Sevruk et al. 2009; Tapiador et al. 2012). Although in situ data have better accuracy, these data are sparse in many regions. During the past decades, reanalysis data have been applied widely in many fields given that these data with high spatial and temporal resolution can effectively compensate for the lack of direct ground observations (Cai et al. 2014; Madonna et al. 2014; Sylla et al. 2010).

Currently, the widespread application of reanalysis data mainly includes NCEP-1 (Kalnay et al. 1996), NCEP-2 (Kanamitsu et al. 2002), ERA-15 (Wernli and Sprenger 2007), ERA-40 (Uppala et al. 2005), ERAInterim (Dee et al. 2011), JRA-25 (Onogi et al. 2005), 
and JRA-55 (Kobayashi et al. 2015). Some earlier studies have reported results based on the performances of several reanalysis data, but most of these studies were limited to particular regions of Asia (Bao and Zhang 2013; Fu et al. 2016; Gao and Hao 2014; Gao et al. 2017; Song and Zhou 2012), within specific seasons (Fan et al. 2013; Huang et al. 2016; Zhang et al. 2015), or within relatively earlier times (Bao and Zhang 2013; Ma et al. 2008, 2009). For example, using independent sounding observations from an enhanced radiosonde network, Bao and Zhang (2013) evaluated the performances of NCEP CFSR, NCEP-1, ERA-Interim, and ERA-40 datasets over the Tibetan Plateau in 1998 and suggested that newer-generation reanalyses (NCEP CFSR and ERA-Interim temperature) generally had better performances than their predecessors (NCEP-1 and ERA-40 temperature) in the Tibetan Plateau. Fu et al. (2016) assessed multiple precipitation products over major river basins of China. Zhang et al. (2015) analyzed the variabilities of winter extreme precipitation in southeast China, whereas the study by Huang et al. (2016) focused on the summer monsoon precipitation over East Asia. Gao and Hao (2014) employed an air temperature of 75 meteorological stations to investigate the ERA-Interim temperature over the Tibetan Plateau during 1979-2010 and found that ERA-Interim temperature could capture the annual cycle very well. Some studies provided more detailed analyses on multiple reanalysis data over China, but their studies mainly covered the analyses based on the data before 2001 (Ma et al. 2008, 2009). Recent studies have suggested that new versions of reanalysis data (e.g., JRA and ERA-Interim) employ more observations to improve the data quality, especially in East Asia and the tropical region ( $\mathrm{Li}$ et al. 2012; Onogi et al. 2005). Also, there are studies suggesting that the warming trend may have slowed down during the first decade of the twenty-first century compared to that before 2000 (Buermann et al. 2007; Cane 2010). Thus, a consecutive study on the performance of reanalysis data covering a much longer period (e.g., the past three decades) is imperative, which can potentially provide a greater insight into the evaluation of reanalysis data.

Among the global reanalysis datasets, ERA-Interim is the latest long-time series global atmospheric reanalysis production of the European Centre for Medium-Range Weather Forecasts (ECMWF; Dee et al. 2011). Compared with earlier ERA-40 data, ERA-Interim data are closer to in situ observations (Adler et al. 2003; Decker et al. 2012; Dee et al. 2011). An important reason is that the ERA-Interim improves the representation of the hydrological cycle and the quality of the stratospheric circulation, as well as the handling of biases and changes in the observing system by employing ERA-40, JRA, and observed data (Dee and Uppala 2009; Dee et al. 2011; Gao and Hao 2014; Li et al. 2012). There is a study reporting that ERA-Interim temperature is slightly better than NCEP-1 data in North America (Mooney et al. 2011). However, there are also some studies suggesting problems with ERA-Interim precipitation and temperature in some particular regions. For example, ERA-Interim precipitation suffered from large biases on the west coasts of America, Africa, and north Canada (Dee et al. 2011; Diaconescu et al. 2018; Di Giuseppe et al. 2013). A study has indicated that biases of ERAInterim data are very severe in Africa because of the scarcity of observed data and defect of the land surface parameterization scheme over the region (AgustíPanareda et al. 2010). These evaluation studies mainly focused on representative continental areas, for example, Europe (de Leeuw et al. 2015; Mooney et al. 2011; Szczypta et al. 2011), Africa (Agustí-Panareda et al. 2010; Diaconescu et al. 2015; Di Giuseppe et al. 2013; Zhang et al. 2013), America (Decker et al. 2012), or the globe (Bosilovich et al. 2008; Dee et al. 2011). Yet the performances of ERA-Interim data in Asia, especially in mainland China, are rarely reported. Besides, many geographers and ecologists used reanalysis data to state the response of vegetation growth to climate change (Cai et al. 2014, 2015). Before using reanalysis data, they usually pay more attention to the spatial performances at seasonal and annual scales. This work potentially helps users of ERA-Interim data to enhance the understanding of the performances of the data in the different regions and seasons of China. Although some previous studies improve our understanding of ERAInterim data in specific regions or seasons (Bao and Zhang 2013; Chen et al. 2014; You et al. 2015), a consecutive study on the performances of ERA-Interim precipitation and temperature in entire mainland China is imperative.

Therefore, the aims of this study are to 1) examine the seasonal and annual spatial patterns and trends of ERAInterim precipitation and temperature over the past three decades, and 2) evaluate the continuous temporal and spatial performances of ERA-Interim data in different ecoclimatic regions and seasons based on the interpolated ground station (STA) data.

\section{Data and methods}

\section{a. Study area}

China covers a vast land area $\left(9.6 \times 10^{6} \mathrm{~km}^{2}\right)$ with a wide range of climates, complex orography, and terrestrial ecosystems (Fig. 1). Also, it is suffering from new 
(a)

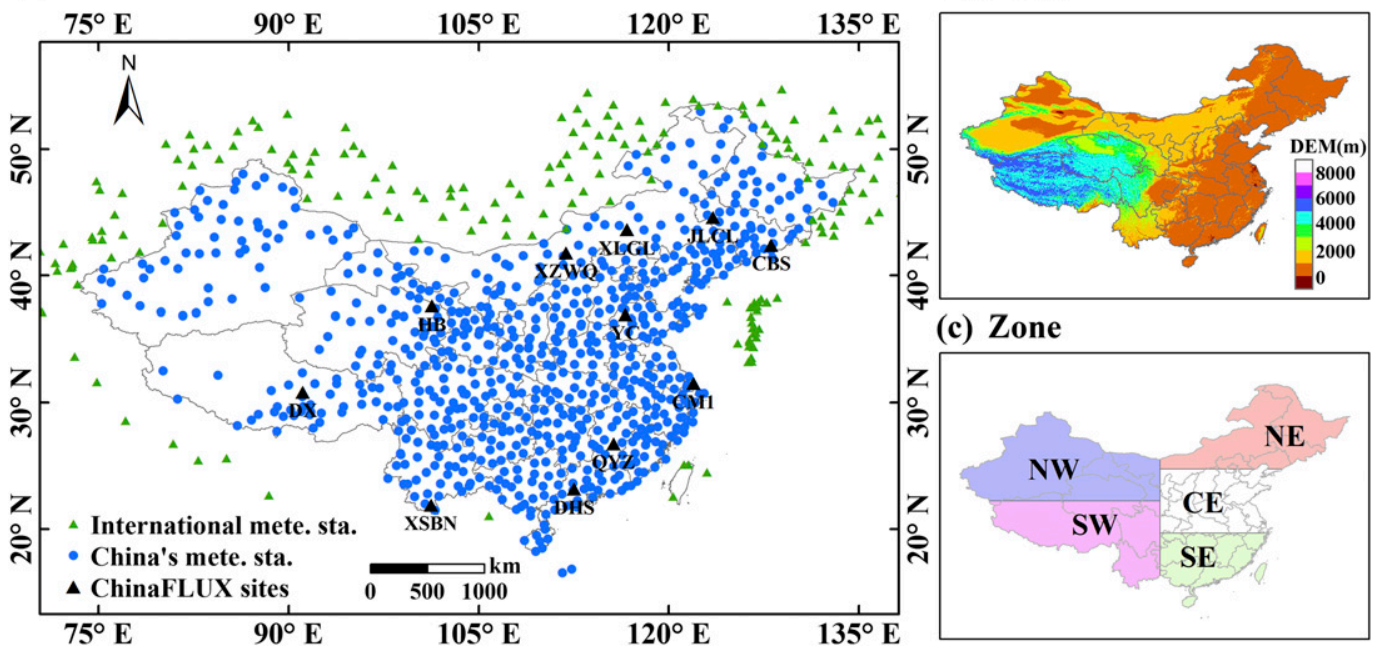

FIG. 1. The distributions of (a) meteorological stations (covering China's meteorological stations and international meteorological stations around mainland China) and ChinaFLUX sites (refer to Table 1). (b) DEM and (c) climatic zones for zonal statistic. NW is northwest China, SW is southwest China, NE is northeast China, CE is central and east China, and SE is southeast China.

challenges posed by climate change. More importantly, spatial distributions of precipitation, which show great heterogeneities, while seasonal temperature exhibits strong variabilities in mainland China, provide a good opportunity for investigating the performances of reanalysis data.

\section{b. Data and processing}

Monthly ERA-Interim precipitation and 2-m surface air temperature are derived from the ERA-Interim atmospheric model and reanalysis system. The system configuration includes a four-dimensional variational analysis with a 12-h analysis window. The spatial resolution of the data is $\sim 79 \mathrm{~km}$ (T255 spectral truncation) on 60 vertical levels from the surface up to $0.1 \mathrm{hPa}$ (Dee and Uppala 2009; Dee et al. 2011). The ECMWF web applications server (http://apps.ecmwf.int) offers a default spatial resolution grid of $0.75^{\circ}$ and also offers other spatial resolutions grids (ranging from $0.125^{\circ}$ to $3^{\circ}$ ) based on a bilinear interpolation technique for continuous parameters (e.g., precipitation and temperature; https://software.ecmwf.int/wiki/display/CKB/ERA-Interim $\% 3 \mathrm{~A}+$ What $+\mathrm{is}+$ the + spatial + reference). In this study, we used reanalysis data with a $0.125^{\circ}$ grid during 1980 2012. The evaluations were thus made on the $0.125^{\circ} \times$ $0.125^{\circ}$ latitude-longitude grid in China. Two reasons are mainly considered for selecting the spatial resolution. First, the $0.125^{\circ}$ grid of reanalysis data is the highest spatial resolution provided by the ECMWF web applications server. Second, this spatial resolution can potentially satisfy the needs of ecological and geographical studies given that they generally desire relatively high-resolution spatial resolution climate data.

Daily precipitation and temperature at 756 meteorological stations in China during 1980-2012 were collected from the National Meteorological Information Center (Fig. 1a; National Meteorological Information Center 2013). Approximately 186 international meteorological stations around mainland China during 19802012 were obtained from the National Oceanic and Atmospheric Administration (ftp://ftp.ncdc.noaa.gov), which was used to enhance the interpolation accuracy of China's border areas (Ma et al. 2015). To ensure data quality, these observed data were first screened by quality control, including the homogeneity analysis of data time series and the removal of data with excessive departures from historical records or the surrounding stations. Using the thin-plate spline interpolation method together with the $0.125^{\circ}$ digital elevation model (DEM; Fig. 1b) as an auxiliary variable (in which the $0.125^{\circ} \mathrm{DEM}$ is derived from a global 1-km SRTM DEM based on projection transformation and bilinear resampling techniques; http://vterrain.org/Elevation/SRTM/), meteorological station data were then converted into daily grid data with a $0.125^{\circ}$ spatial resolution (Hutchinson et al. 2009). Finally, interpolated precipitation and temperature station data were aggregated from a daily to monthly scale (hereinafter referred to as STA data) consistent with the spatial and temporal resolutions of ERA-Interim data. The interpolation method and data quality have already been validated in earlier studies (Liu et al. 2012; Ma et al. 2015; Yuan et al. 2015). To further 
TABLE 1. Brief descriptions of 11 flux tower sites from ChinaFLUX in this study.

\begin{tabular}{lcccc}
\hline \multicolumn{1}{c}{ Site (abbreviation) } & Lat $\left({ }^{\circ} \mathrm{N}\right)$ & Lon $\left({ }^{\circ} \mathrm{E}\right)$ & Alt $(\mathrm{m})$ & Data period \\
\hline Changbaishan (CBS) & 42.40 & 128.10 & 738 & $2003-05$ \\
Qianyanzhou (QYZ) & 26.75 & 115.67 & 102 & $2003-05$ \\
Dinghushan (DHS) & 23.17 & 112.53 & 300 & $2003-05$ \\
Xishuangbanna (XSBN) & 21.90 & 101.27 & 756 & 28 \\
Yucheng (YC) & 36.95 & 116.60 & 3300 & $2003-05$ \\
Haibei (HB) & 37.62 & 101.32 & 1100 & $2003-05$ \\
Xilinguole (XLGL) & 43.63 & 116.70 & 1450 & $2003-04$ \\
Siziwangqi (SZWQ) & 41.79 & 111.89 & 4250 & $2011-12$ \\
Dangxiong (DX) & 30.83 & 91.12 & 160 & $2003-04$ \\
Changling (JLCL) & 44.58 & 123.50 & 0 & $2007-08$ \\
Chongming (CM1) & 31.52 & 121.96 & & 2005 \\
\hline
\end{tabular}

validate the performances of interpolated data in this study, we also employed meteorological observations of 11 flux towers from the ChinaFLUX (Fig. 1 and Table 1). Flux towers usually provided half-hourly observed data. We thus used the following steps to obtain monthly data. First, half-hourly data were aggregated to daily data, if the number of half-hourly data was greater than 40 (ensure that there are more than $85 \%$ available data) in each day. Otherwise, the corresponding day was set as missing data. In the same way, daily data were then aggregated to monthly data, if the number of daily data was more than 26 days in each month. If not, the corresponding month was set as missing data. Finally, 308 precipitation months and 311 temperature months were selected as independent data to validate the performances of STA data.

In addition, it should be clearly noted that, according to the previous references (Dee et al. 2011; Uppala et al. 2005), we knew ERA-Interim only assimilated a small part of the surface-observed temperature from China's stations. However, there is an important but difficult-toanswer question regarding which stations and what years might be used by ERA-Interim for assimilation purposes. The same question has been mentioned in a recent reference (Gao et al. 2012). Similarly, according to the information from the ECMWF and the statistical significance of the differences of two temperature data shown in the following section, it can be implied that the majority of China's stations are not used by ERAInterim. We can thus regard ERA-Interim and STA temperature as completely independent datasets.

\section{c. Statistical analysis}

This study first spatially examined the annual and seasonal mean precipitation and temperature. The spatial differences (bias) of ERA-Interim and STA data were then investigated. The detailed features of differences of ERA-Interim and STA data were further analyzed in five climatic zones. After those, the skill score
(S index) was employed to display the multiyear mean departures of both datasets (Hirota et al. 2011; Taylor 2001). The empirical orthogonal function (EOF) analysis (Björnsson and Venegas 1997; North et al. 1982) and the trend analysis (Wang et al. 2017) were also used to check the consistency of both datasets. The appendix lists the detailed statistical methods.

\section{Results}

\section{a. The performances of interpolated data}

The relationships between flux tower-based observations and STA data were analyzed in this section (Fig. S1 in the supplemental material). A good performance was observed in the interpolated precipitation with a coefficient of determination $R^{2}$ of 0.79 , bias of $14.4 \%$, and root-mean-square error (RMSE) of $65.1 \%$. In contrast, interpolated temperature performed a stronger agreement with flux tower-based observations, with an $R^{2}$ of 0.99 , bias of $0.6 \mathrm{~K}$, and RMSE of $1.2 \mathrm{~K}$.

\section{b. Comparisons of ERA-Interim and STA precipitation}

Both annual total precipitation (the 1980-2012 mean at each grid point) from ERA-Interim and from STA data decreased gradually from southeast China to northwest China (Figs. 2a,f), ranging from more than $2500 \mathrm{~mm}$ to $5 \mathrm{~mm}$ for ERA-Interim precipitation, and from $2150 \mathrm{~mm}$ to $34 \mathrm{~mm}$ for STA precipitation. Compared with STA precipitation, ERA-Interim presented higher precipitation amounts, especially in the southeastern Tibetan Plateau (region 1 in Fig. 2a), Sichuan basin (region 2 in Fig. 2a), and southeast China (region 3 in Fig. 2a). Annual precipitation amounts in these regions were generally greater than $2500 \mathrm{~mm}$. However, annual precipitation amounts of STA in corresponding regions were around $2000 \mathrm{~mm}$. For seasonal total precipitation, ERA-Interim data showed similar spatial 
(a) Annual

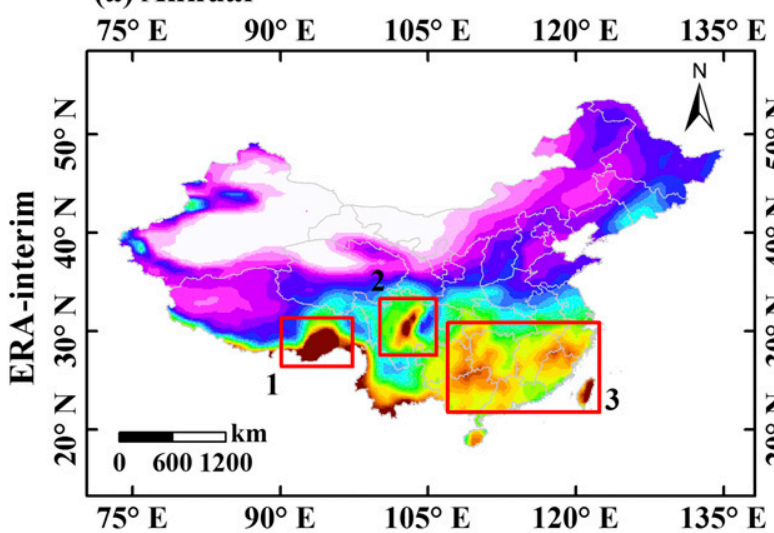

(f) Annual

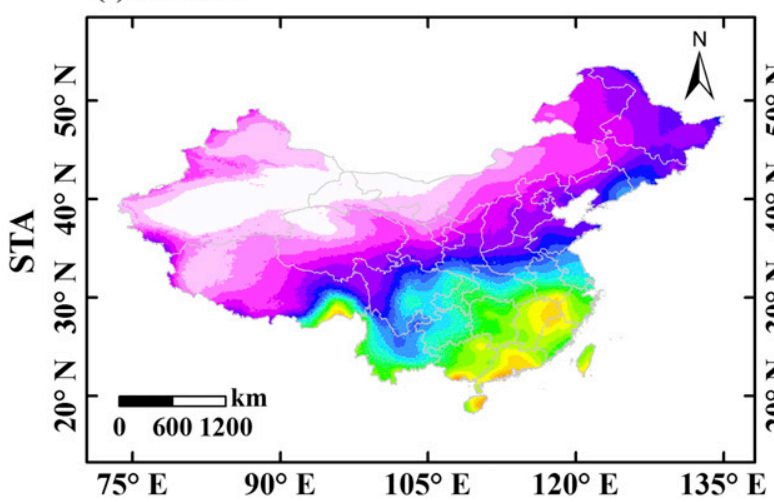

(b) Spring

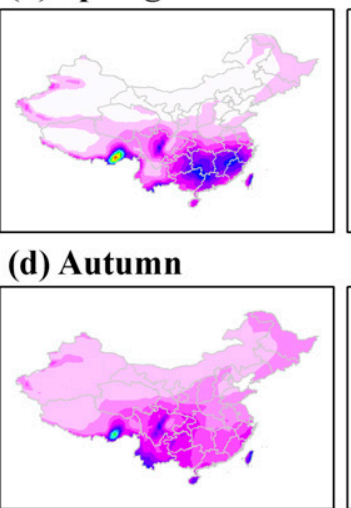

(g) Spring

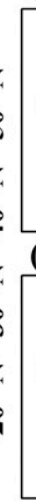

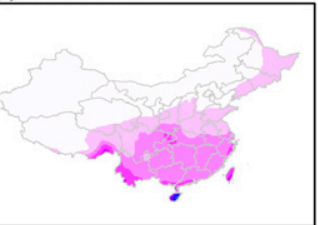

(i) Autumn (c) Summer

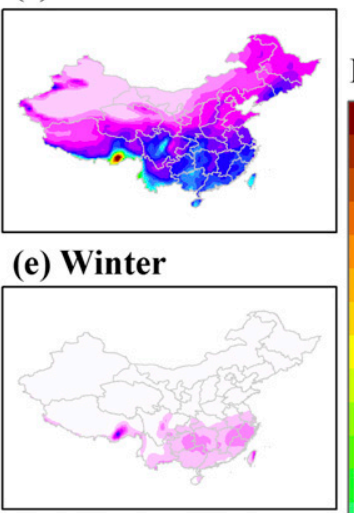

(h) Summer

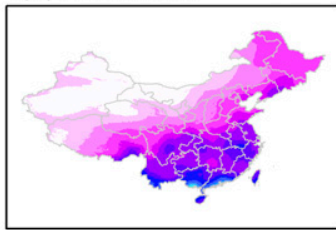

(j) Winter
P. $(\mathbf{m m})$

2500

2000

1500

1000

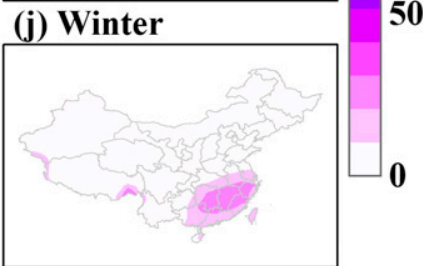

500

FIG. 2. Spatial patterns of annual and seasonal total precipitation (1980-2012 average). (a)-(e) ERA-Interim data and (f)-(j) STA data.

patterns with STA data but precipitation amounts varied. Major precipitation focused on summertime (June, July, and August). Winter (December, January, and February) precipitation amounts were the lowest and mainly concentrated on southeast China.

Figures 3a-e show spatial bias values between ERAInterim precipitation and STA precipitation. At the annual and seasonal scales, bias values were usually less than $\pm 50 \%$ in eastern China. In contrast, most bias values in southwest China were positive and generally greater than $100 \%(p<0.05)$, suggesting that ERAInterim products appeared to overestimate precipitation in this region, especially in springtime and wintertime.

To understand the contributions of different regions and different seasons to annual differences, we investigated the differences between ERA-Interim data and STA data at five climatic zones (Fig. 1c) and four seasons, respectively. Precipitation of the ERA-Interim product was usually overestimated (Fig. S2 in the supplemental material). At the seasonal scales, differences of precipitation in southwest China were the largest (from $226.0 \pm 29.7 \mathrm{~mm}$ in summer to $38.8 \pm 7.6 \mathrm{~mm}$ in winter) among all seasons. The second was in southeast China, with the difference of annual total precipitation being $194.7 \pm 101.8 \mathrm{~mm}$. The other three regions presented small differences of less than $50 \mathrm{~mm}$. Summertime and springtime contributed more to the annual difference.

At the annual scale, ERA-Interim total precipitation in eastern China performed well, with the $S$-index values greater than 0.6. The S-index values in northeast China were generally higher than 0.7 , suggesting the reliability of ERA-Interim precipitation in this region. At the seasonal scales, eastern China had higher S-index values than western China. Figure $3 \mathrm{~h}$ suggests that the summer $\mathrm{S}$ index contributed more to the annual $\mathrm{S}$ index in view of their spatial patterns. In central and eastern China, summer S-index values were less than 0.6; the other three seasons, however, showed higher S-index values in these regions. Mostly, winter S-index values in central and eastern China and southeast China were higher than 0.6, implying that ERA-Interim precipitation had a strong consistency with STA precipitation. However, most S-index values of western China were less than 0.3 for all four seasons.

Compared to STA precipitation, ERA-Interim had larger precipitation amounts at annual and seasonal scales (Fig. 4). However, interannual changes of ERA-Interim 
(a) Annual
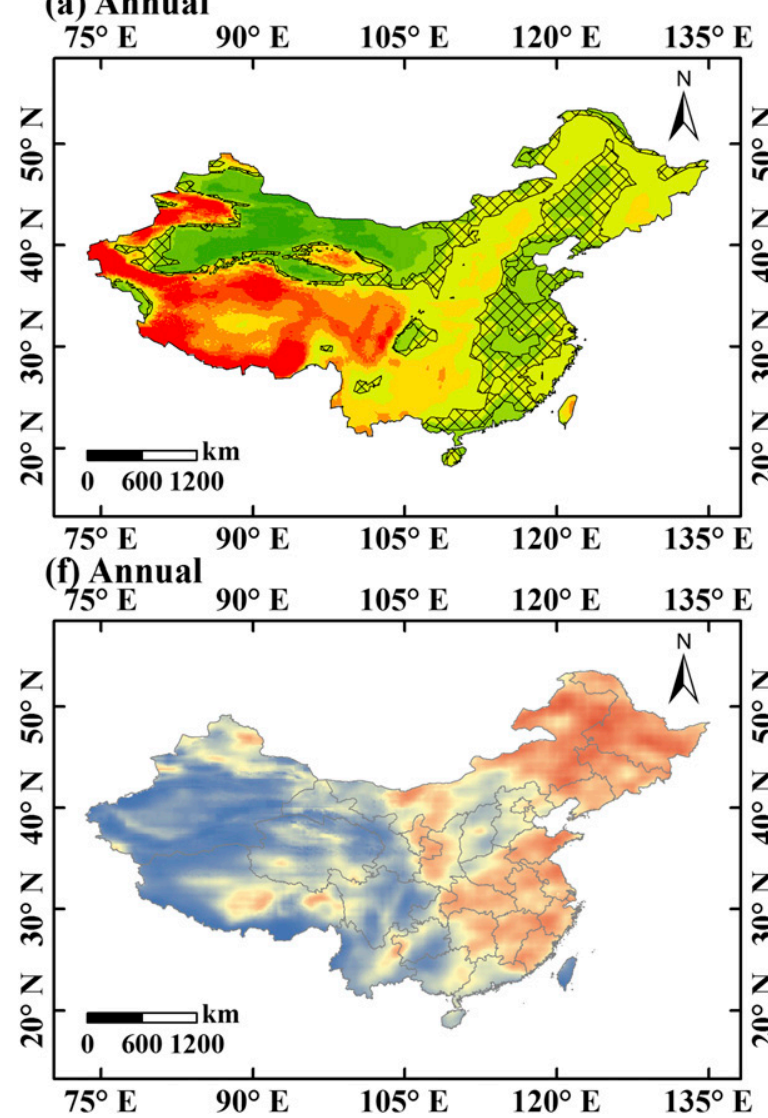

(b) Spring

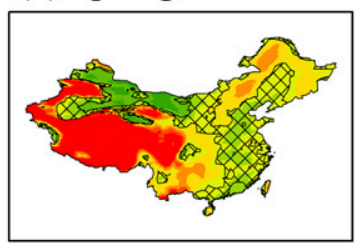

(d) Autumn

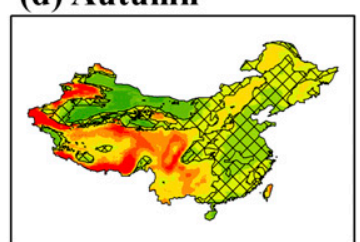

(g) Spring

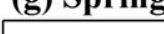 \\ (g) Spring}

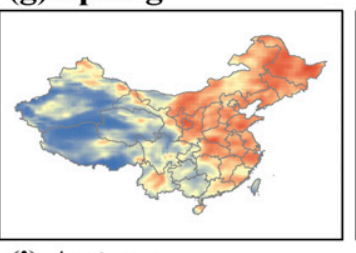

(i) Autumn

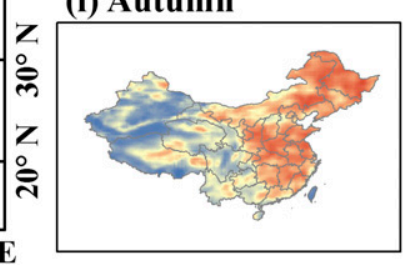

(c) Summer

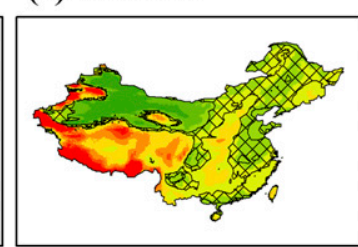

(e) Winter

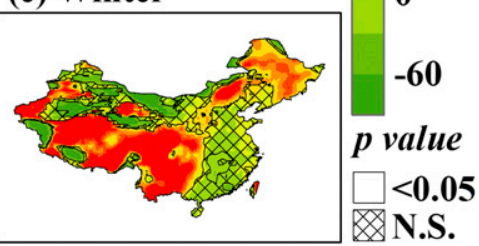

(h) Summer

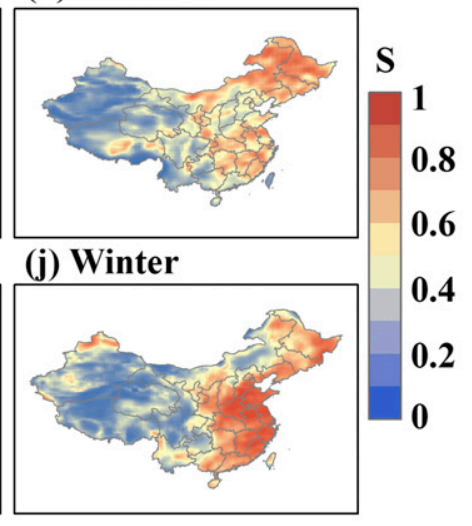

Bias

\section{6 0.4 .2

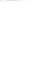

FIG. 3. (a)-(e) The annual and seasonal differences (bias and the significance at the 0.05 level) and (f)-(j) S index between ERA-Interim precipitation and STA precipitation during the period 1980-2012. N. S. means no statistical significance.

annual and seasonal precipitation were well consistent with those of STA, with $R$ ranging from 0.757 to 0.937 $(p<0.01)$. All annual and seasonal precipitation, except STA winter precipitation, presented decreasing trends during 1980-2012, but they were statistically insignificant $(p>0.05)$. Spring and autumn (more than $\left.3 \mathrm{~mm} \mathrm{decade}^{-1}\right)$ contributed slightly more than summer and winter (lower than $2 \mathrm{~mm} \mathrm{decade}^{-1}$ ) to the annual decreasing trend over the past 33 years. The change of winter precipitation was the weakest, with $0.4 \mathrm{~mm} \mathrm{decade}^{-1}$ for STA and $-0.4 \mathrm{~mm} \mathrm{decade}^{-1}$ for ERA-Interim. It is worth noting that ERA-Interim spring precipitation reduced more sharply, with $6.2 \mathrm{~mm} \mathrm{decade}^{-1}$ relative to STA spring precipitation with a lower rate of $3.2 \mathrm{~mm}_{\text {decade }}{ }^{-1}$.

Table 2 and Fig. 4 show that ERA-Interim precipitation usually presented greater standard deviation (STD) values (from $74.1 \mathrm{~mm}$ in wintertime to $304.2 \mathrm{~mm}$ in summertime) than STA precipitation (from $64.0 \mathrm{~mm}$ in wintertime to $225.3 \mathrm{~mm}$ in summertime, and summer precipitation had stronger spatial variabilities because of larger averaged precipitation amounts), but their
STD showed consistent trends at the corresponding annual and seasonal scales. At the annual scale, the slope values of two STD were -11.4 and $-8.3 \mathrm{~mm} \mathrm{decade}^{-1}$, suggesting decreasing spatial variabilities of annual precipitation. Similar decreasing spatial variabilities were also observed in spring, autumn, and winter. However, summer slope values performed increasing spatial variabilities with $1.8 \mathrm{~mm} \mathrm{decade}^{-1}$ for ERA-Interim STD and $2.1 \mathrm{~mm} \mathrm{decade}^{-1}$ for STA STD.

Figure 5 shows the first three leading EOF modes and their corresponding principal components (PCs) for ERA-Interim and STA annual precipitation. The percentages of the total variance explained by the first three leading EOF modes were over $49 \%$ for ERA-Interim data and over $46 \%$ for STA data. The corresponding EOF modes between ERA-Interim and STA annual precipitation accounted for similar percentages of total variance (e.g., $25.3 \%$ vs $25.0 \%$ for EOF1, $15.8 \%$ vs $14.3 \%$ for $\mathrm{EOF} 2$, and $8.3 \%$ vs $7.3 \%$ for $\mathrm{EOF} 3$ ). Although most EOF modes of ERA-Interim annual precipitation captured those of STA, the EOF patterns of ERA-Interim and STA annual precipitation showed 


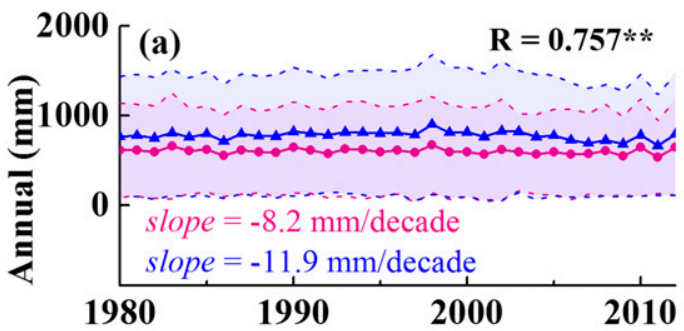

\section{Precipitation}

$\rightarrow$ STA $\rightarrow$ ERA-Interim
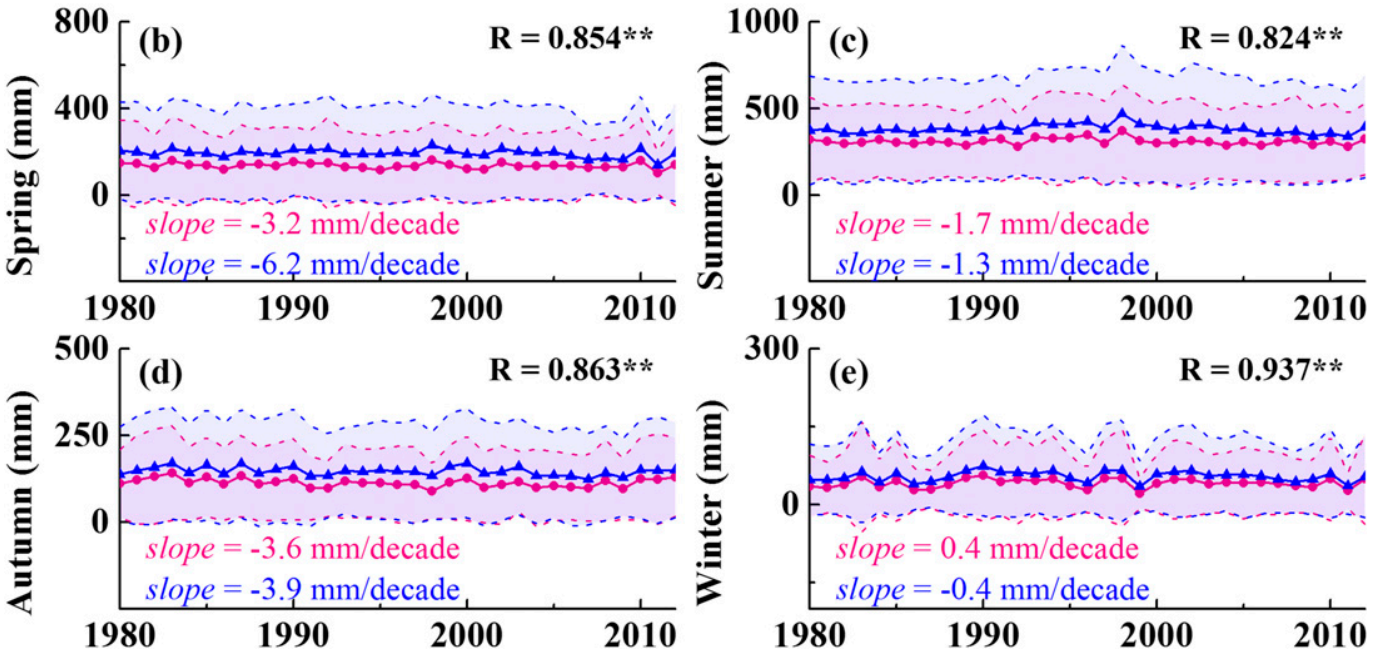

FIG. 4. Interannual change of annual and seasonal precipitation over China during the period 1980-2012. The pink and blue lines are spatial mean STA and ERA-Interim precipitation. The pink and blue zones are the spatial STA STD and ERA-Interim precipitation. The single and double asterisks indicate significance at the 0.05 and 0.01 level, respectively.

large differences in some regions. For EOF1, most regions of ERA-Interim annual precipitation showed positive values except for the eastern Tibetan Plateau, while the regions ranging from $30^{\circ}$ to $40^{\circ} \mathrm{N}$ of STA annual precipitation showed negative values. Combined with $\mathrm{PC} 1$, when their $\mathrm{PC} 1$ s were both negative, annual precipitation in the regions ranging from $30^{\circ}$ to $40^{\circ} \mathrm{N}$ decreased for ERA-Interim data but increased for STA data, and vice versa. For EOF2, the opposite regions mainly focused on northeastern and western China. As shown in Figs. 5g-i, not only did EOF3 of ERA-Interim and STA annual precipitation show large spatial differences, but PC3 of ERA-Interim and STA annual precipitation also showed different fluctuations in some years. Similarly, for four seasonal EOF modes, the corresponding EOF modes between ERA-Interim and STA seasonal precipitation accounted for similar percentages of total variance, but the distributions of EOF modes showed large differences (Figs. S3-S6 in the supplemental material).

Figure 6 shows that overall trends of ERA-Interim data were basically consistent with STA data, but spatial

TABLE 2. The magnitudes of variability (using spatial STD) of precipitation between ERA-Interim and STA data at seasonal and annual scales. Mean and slope are the avg and trend of each climatic variable during 1980-2012. The single and double asterisks indicate significance at the 0.05 and 0.01 level, respectively.

\begin{tabular}{|c|c|c|c|c|}
\hline & \multicolumn{4}{|c|}{ Precipitation } \\
\hline & \multicolumn{2}{|c|}{ ERA-Interim spatial STD } & \multicolumn{2}{|c|}{ STA spatial STD } \\
\hline & Mean $(\mathrm{mm})$ & Slope $\left(\mathrm{mm} \mathrm{decade} \mathrm{de}^{-1}\right)$ & Mean $(\mathrm{mm})$ & Slope $\left(\mathrm{mm} \mathrm{decade}^{-1}\right)$ \\
\hline Spring & 214.6 & $-9.01 *$ & 165.3 & $-9.39 *$ \\
\hline Summer & 304.2 & 1.80 & 225.3 & 2.08 \\
\hline Autumn & 143.4 & $-6.07 * *$ & 107.6 & -2.87 \\
\hline Winter & 74.1 & -0.22 & 64.0 & -0.88 \\
\hline Annual & 679.0 & -11.37 & 499.9 & -8.03 \\
\hline
\end{tabular}


ERA-Interim

(a) EOF1 (25.3\%)
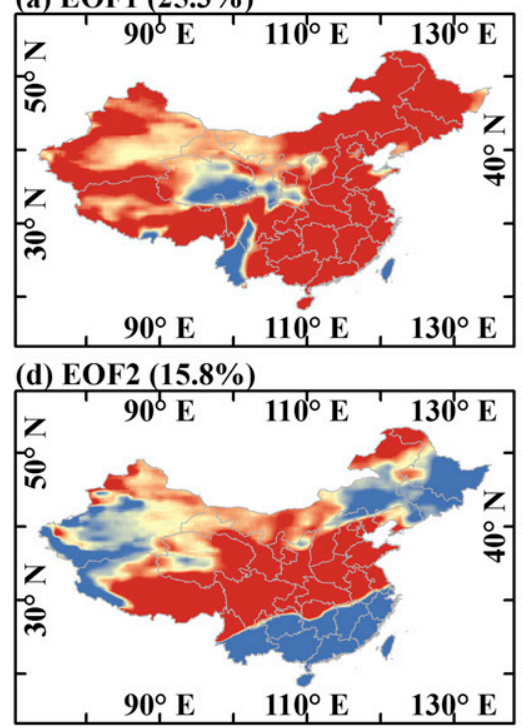

(g) EOF3 (8.3\%)

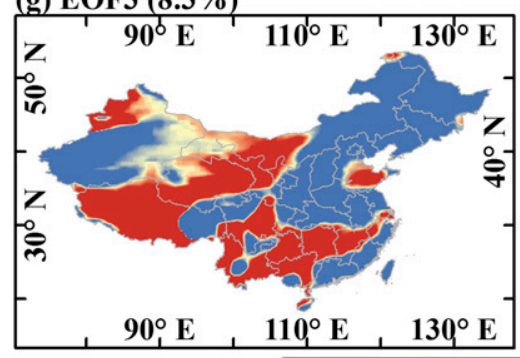

STA
(b) EOF1 (25.0\%)
TA

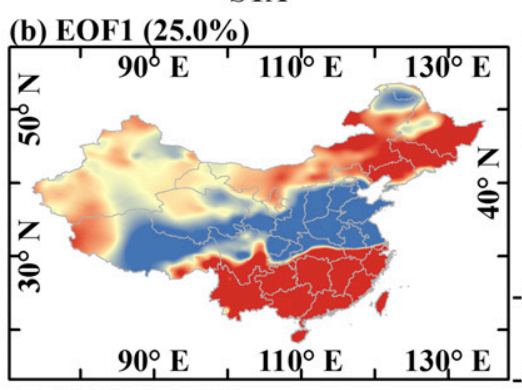

(e) EOF2 (14.3\%) $110^{\circ} \mathrm{E}$
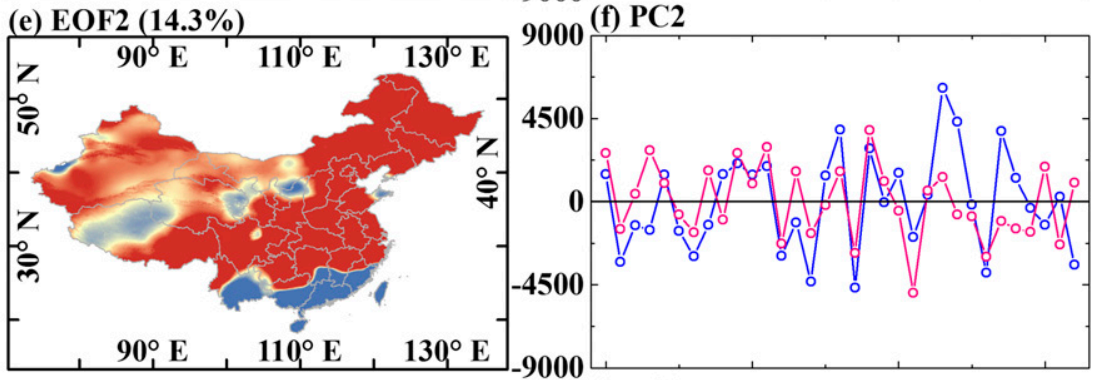

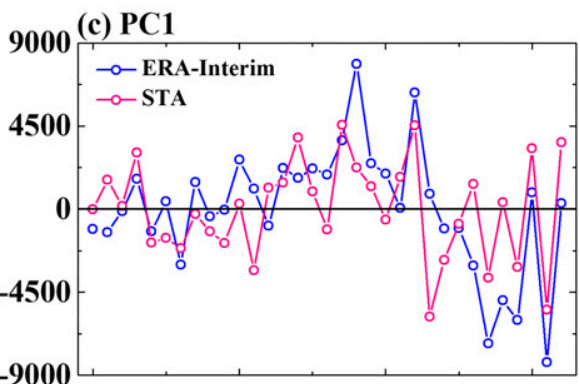

(f) $\mathrm{PC} 2$

(h) $\operatorname{EOF3~(7.3\% )~}$

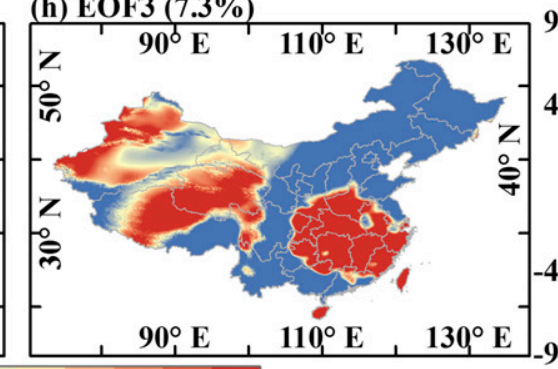

9000 (i) PC3
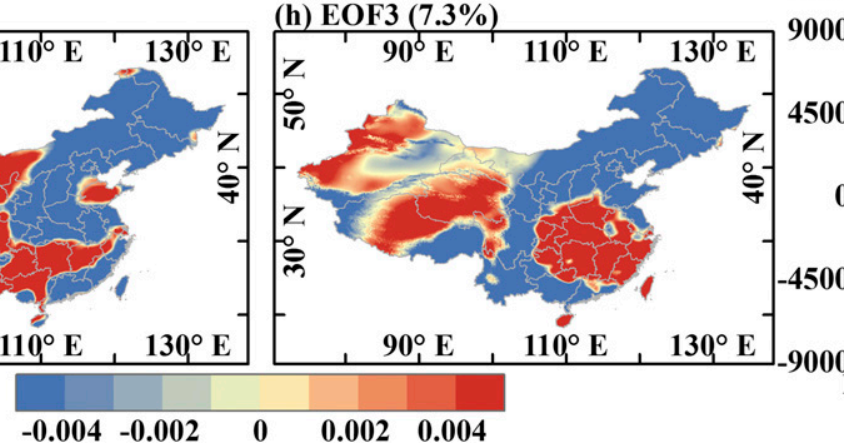

FIG. 5. First three leading eigenvectors and (c),(f),(i) corresponding PCs derived from the EOF analysis of (a),(d),(g) ERA-Interim and (b),(e),(h) STA annual precipitation over mainland China during the period 1980-2012.

trend patterns of precipitation showed strong differences in some regions. For annual total precipitation, ERA-Interim precipitation amounts decreased significantly, with $\sim 100 \mathrm{~mm} \mathrm{decade}^{-1}(p<0.05)$ in some regions of south China; however, these significant decreasing trends were not observed in STA precipitation in the corresponding regions. Besides, precipitation of some regions showed opposite trends, such as west Xinjiang (region 1 of Fig. 6a) and west Yunnan (region 2 of Fig. 6a). In the east Tibetan Plateau, increasing trends of ERA-Interim precipitation emerged significantly stronger than those of STA precipitation. In springtime, ERA-Interim precipitation amounts in southeastern coastal areas significantly decreased with $\sim 100 \mathrm{~mm} \mathrm{decade}^{-1}(p<0.05)$; however, only about one-fifth of the corresponding area revealed significantly reducing trends in STA precipitation. In the other three seasons, although major trends of ERA-Interim precipitation showed good agreements with those of STA precipitation, significant changes in areas were strongly varied.

\section{c. Comparisons of ERA-Interim and STA temperature}

ERA-Interim annual and seasonal mean temperature presented relatively better agreements with STA temperature (Fig. 7). Annual mean temperature decreased from southeast China $\left(\sim 303 \mathrm{~K}\right.$ or $\left.30^{\circ} \mathrm{C}\right)$ to northwest China $\left(\sim 273 \mathrm{~K}\right.$ or $\left.0^{\circ} \mathrm{C}\right)$. Annual mean temperature in the Tibetan Plateau (lower than $278 \mathrm{~K}$ or $5^{\circ} \mathrm{C}$ ) was usually lower than other regions because of relative higher elevation. At seasonal scale, summer mean temperature had the highest value $\left(\sim 293 \mathrm{~K}\right.$ or $\left.20^{\circ} \mathrm{C}\right)$, while winter mean temperature had the lowest value $\left(\sim 268 \mathrm{~K}\right.$ or $\left.-5^{\circ} \mathrm{C}\right)$. Spatial decreasing patterns were also observed from southeast China to northwest China for four seasonal mean temperature values.

Annual bias values were less than $\pm 2 \mathrm{~K}$ in lowerelevation areas (Figs. 8a-e). Yet ERA-Interim products largely underestimated the temperature of the Tibetan 
(a) Annual

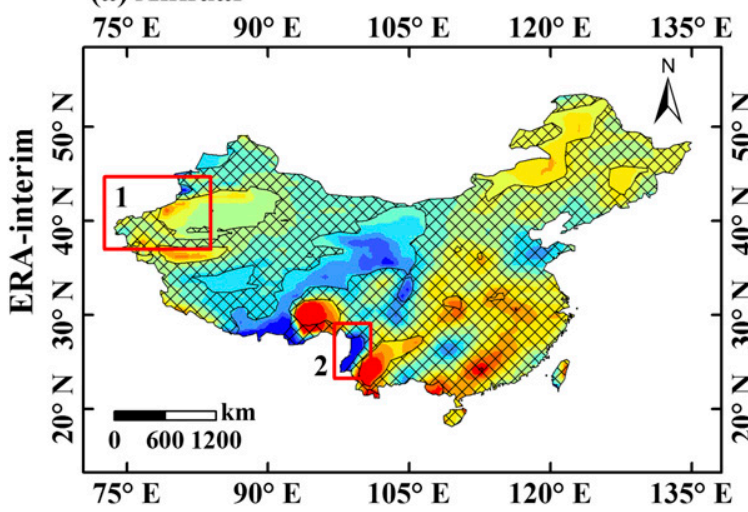

(f) Annual

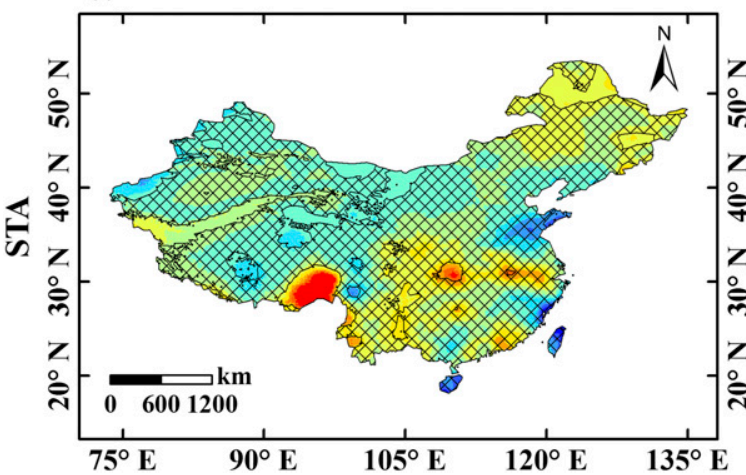

(b) Spring

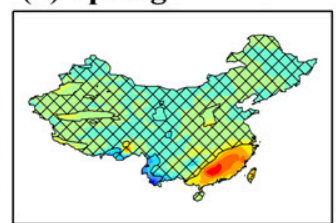

(d) Autumn

(d) Autumn

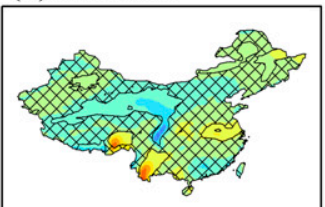

(g) Spring

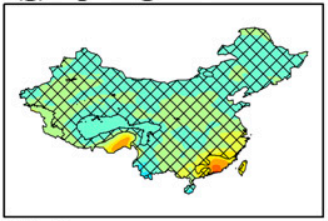

(i) Autumn

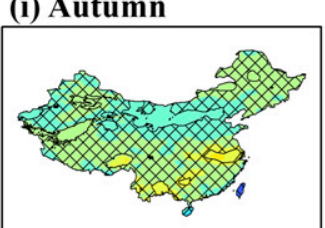

(c) Summer

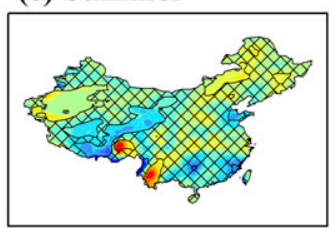

(e) Winter

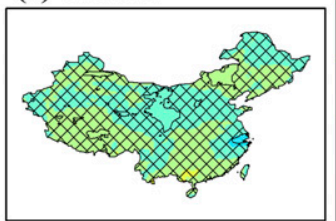

(h) Summer

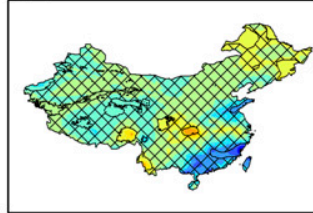

(j) Winter

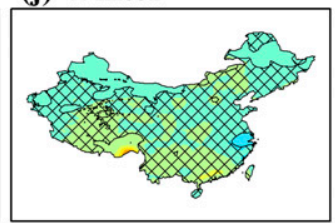

Trend ( $\mathrm{mm} /$ decade)

100

60

20

$-20$

$-60$

$-100$

p value

$\square<0.05$

$\otimes 0.05$

FIG. 6. Trends of annual and seasonal total precipitation for each pixel during the period 1980-2012 and their significance at the 0.05 level (N. S. means no statistical significance) for (e)-(e) ERA-Interim data and (f)-(j) STA data.

Plateau, as most annual bias values were less than $3 \mathrm{~K}$. Most regions $(80 \%-90 \%$ of all pixels) showed two data had significant differences $(p<0.05)$. Seasonal bias values presented similar annual patterns in most regions. Particularly, a positive bias of winter temperature was observed over the far northwestern and northeastern parts of China (Fig. 8e). Probably, this is due to the influence of continental cold air masses and strong near-surface temperature inversions observed over those parts in winter associated with influence of Siberian high, while ERA-Interim failed to adequately reproduce those temperature conditions in the lower troposphere.

To understand the contributions of different regions and different seasons to annual differences, the differences between ERA-Interim data and STA data at five climatic zones (Fig. 1c) and four seasons were also investigated, respectively. The temperature of the ERAInterim product was generally underestimated (Fig. S7 in the supplemental material). Northwest China and southwest China both exhibited big differences, with differences of annual mean temperature being $3.1 \pm 0.4 \mathrm{~K}$ and $5.2 \pm 0.4 \mathrm{~K}$, respectively, and thus contributed more than the other three regions to the difference of entire
China, with $2.6 \pm 0.3 \mathrm{~K}$. Unlike differences of seasonal precipitation, those of seasonal temperature in the same region were relatively small.

Figures $8 \mathrm{f}-\mathrm{j}$ illustrate that most annual S-index values were greater than 0.8 in lower-elevation areas, suggesting that ERA-Interim temperature was more credible in these regions. Nevertheless, one should consider the uncertainty of ERA-Interim temperature in higherelevation areas in view of the lower S-index values, for example, the Tibetan Plateau. The distributions of four seasonal S-index values were very similar to annual S-index patterns. Particularly, ERA-Interim spring and summer temperature had a better relationship with that of STA, as S-index values were higher than 0.6 in the southwestern and central Tibetan Plateau.

Negative bias values between ERA-Interim and STA temperature were observed at the annual and seasonal scales (Fig. 9). Changes of temperature were generally significant during 1980-2012, and the time series of temperature showed higher $R$ with $0.889-0.932$. At the annual scale, STA temperature increased with $0.46 \mathrm{~K} \mathrm{decade}^{-1}(p<0.01)$, but a lower rate of $0.17 \mathrm{~K} \mathrm{decade}^{-1}(p<0.01)$ was noted for ERA-Interim. For STA, spring temperature increased significantly 
(a) Annual

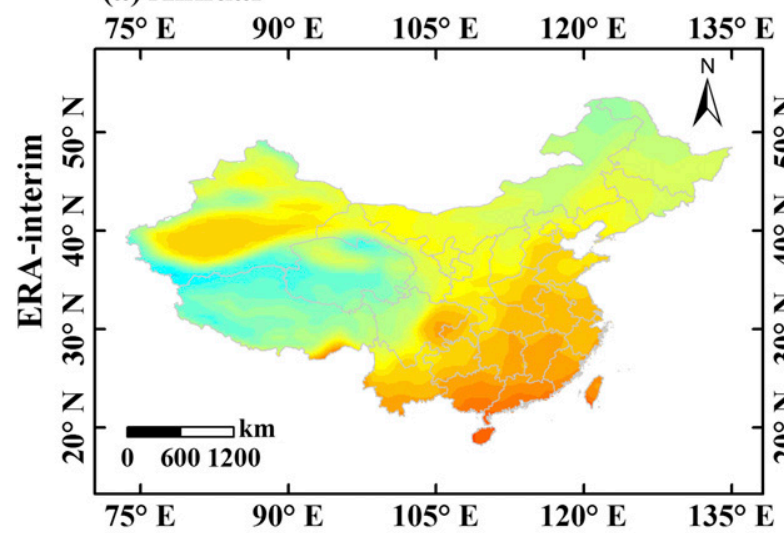

(f) Annual

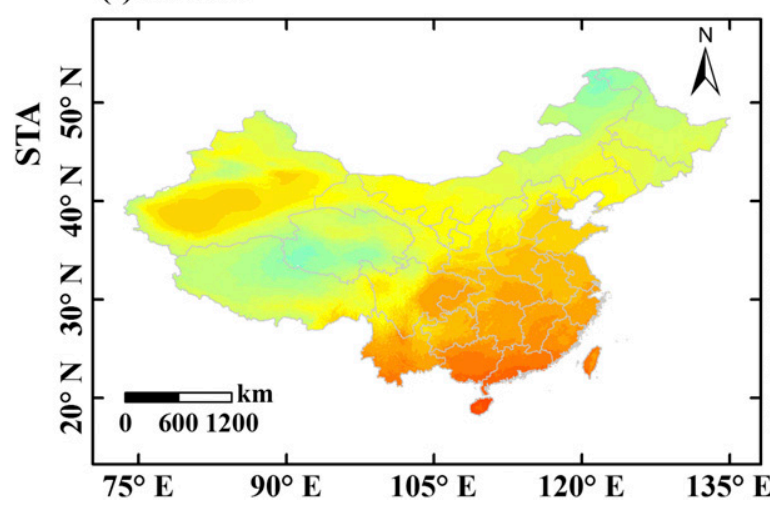

(b) Spring

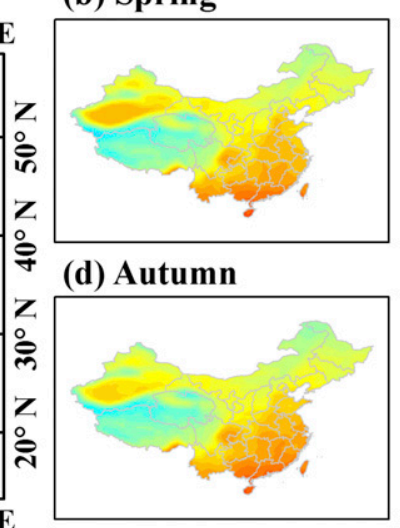

(g) Spring

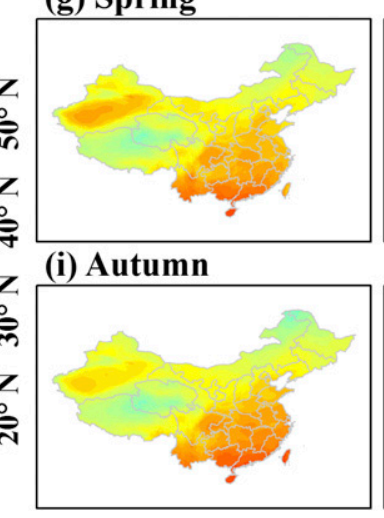

(c) Summer

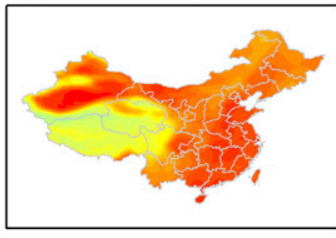

(e) Winter

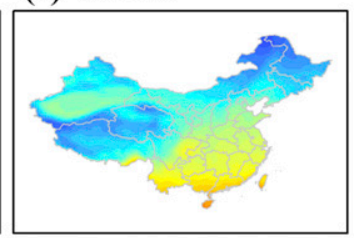

(h) Summer

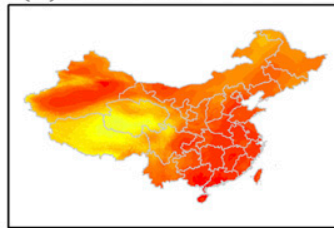

(j) Winter

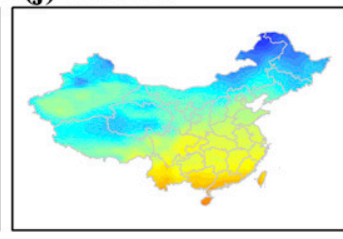

T. (K) $>303$

293

283

273

263

253

$<243$

FIG. 7. As in Fig. 2, but for mean temperature.

with $0.53 \mathrm{Kdecade}^{-1}(p<0.01)$. The second were autumn and summer temperatures, with $0.48 \mathrm{~K} \mathrm{decade}^{-1}$ $(p<0.01)$ and $0.47 \mathrm{~K} \mathrm{decade}^{-1}(p<0.01)$, respectively. The warming trend of winter temperature was the lowest with $0.37 \mathrm{Kdecade}^{-1}(p<0.05)$. Trends of four ERA-Interim seasonal temperatures were all less than those of corresponding STA seasonal temperatures. ERA-Interim spring, summer, and autumn temperatures showed similar significant warming trends $\left(\sim 0.2 \mathrm{~K} \mathrm{decade}^{-1}, p<0.05\right)$ and their trends were all greater than that of the winter temperature with only $0.03 \mathrm{~K} \mathrm{decade}^{-1}(p>0.05)$.

Table 3 and Fig. 9 show that larger spatial variabilities were observed in STD values of ERA-Interim temperature, which were mostly 1.2-1.4 times greater than those of STA temperature. The STD of ERA-Interim and STA temperatures showed the largest difference in summer and the smallest difference in winter. Although the trends of all STD of ERA-Interim and STA temperatures changed weakly, their STD presented opposite trends in most cases. The slope values of the ERA-Interim STD were all positive, suggesting increasing spatial variabilities at the annual and seasonal scales. However, STA STD only increased in winter. Particularly, STA STD showed significantly decreasing spatial variabilities at autumn and annual scales, with 0.08 and $0.06 \mathrm{~K} \mathrm{decade}^{-1}(p<0.05)$, respectively.

Figure 10 shows the first three leading EOF modes and corresponding PCs for ERA-Interim and STA annual temperature. The percentages of the total variance explained by the first three leading EOF modes were about $73 \%$ for ERA-Interim data and over $82 \%$ for STA data. Most regions of ERA-Interim and STA annual temperature showed similar patterns in the first and second EOF modes, although the percentages of total variance had large differences (e.g., $46.9 \%$ vs $62.1 \%$ for EOF1). The warming trends in China could be captured by EOF1 of ERA-Interim annual temperature, but that resulting from ERA-Interim was somewhat weaker than that from STA, especially in high mountain areas. Unlike the first EOF modes, EOF2 and EOF3 showed large differences in southeast China. However, the PC2 and PC3 of ERA-Interim and STA annual temperature presented relatively consistent changes. Particularly, for four seasonal EOF modes, the corresponding EOF modes between ERA-Interim and STA seasonal 
(a) Annual

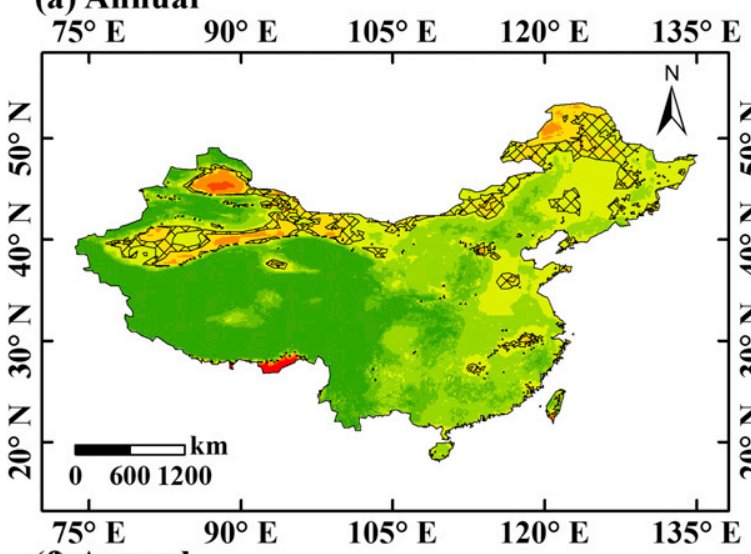

(f) Annual

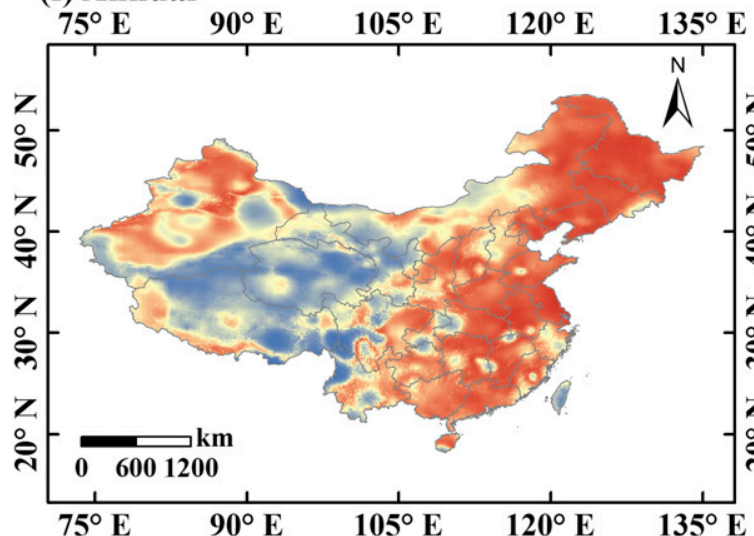

$\begin{array}{lllll}75^{\circ} \mathrm{E} & 90^{\circ} \mathrm{E} & 105^{\circ} \mathrm{E} & 120^{\circ} \mathrm{E} & 135^{\circ} \mathrm{E}\end{array}$ (b) Spring

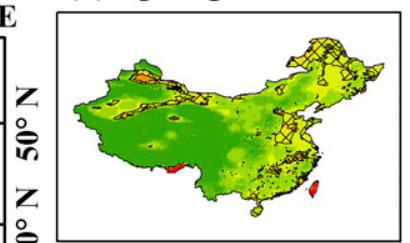

(d) Autumn

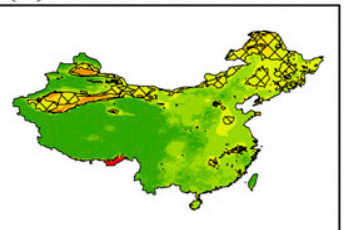

(g) Spring

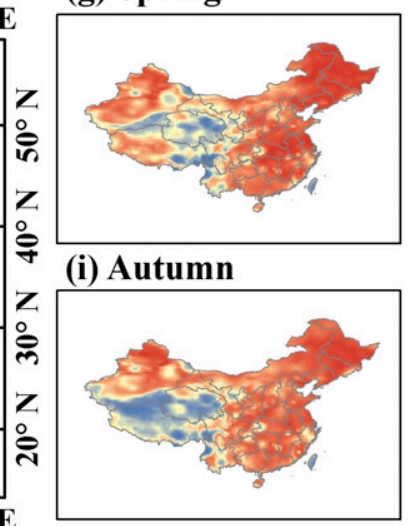

(c) Summer

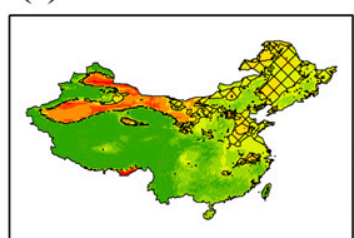

(e) Winter

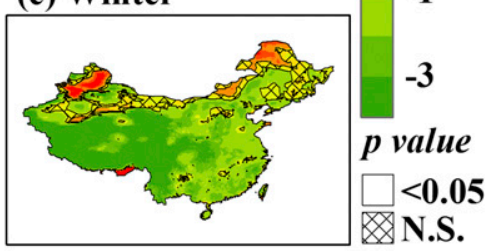

(h) Summer

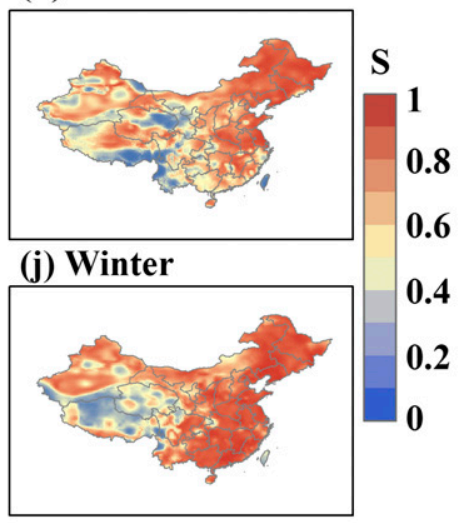

Bias

(K)

3

1

$-1$

$<0.05$

N.S.
FIG. 8. As in Fig. 3, but for temperature. temperature accounted for similar percentages of total variance in spring and autumn, while relative large differences of the percentages of total variance were observed in summer and winter (Figs. S8-S11 in the supplemental material). The differences from summer and winter could contribute more to annual differences.

Figure 11 shows that spatial trend patterns of temperature showed strong differences in some regions. Significant areas of ERA-Interim temperature change $\left(>1 \mathrm{~K} \mathrm{decade}^{-1}, p<0.05\right)$ are mainly located in eastern coastal regions and western inland regions. Annual and seasonal mean temperature of these areas warmed significantly $(p<0.05)$. Yet ERA-Interim winter mean temperature presented a significant cooling trend $\left(>0.5 \mathrm{~K} \mathrm{decade}^{-1}\right)$ in north China during 1980-2012. Compared with ERA-Interim temperature, the warming trends of STA temperature were much stronger over the past 33 years, especially in western high mountainous regions. Increasing trends of temperature exceeded $2 \mathrm{Kdecade}^{-1}(p<0.05)$. There are STA temperatures of some regions that presented significant cooling trends with more than $0.5 \mathrm{~K} \mathrm{decade}^{-1}(p<0.05)$, for example, southwestern forest regions. In the Tibetan Plateau, the STA winter mean temperature showed a significant warming trend with $0.85 \mathrm{~K}$ decade $^{-1}(p<0.05)$; however, the significant change in ERA-Interim winter mean temperature was not observed.

\section{Discussion}

In this study, meteorological station data were first converted into grid data, and then the evaluations were investigated based on these grid data. However, some suggested that the evaluations based on the station data should be calculated, and then the elevation results were converted into the grid data. It is worth noting that there is a debate for which methods are more appropriate. Many studies suggest that it would be more appropriate to grid the data first and then to compare them (Ma et al. 2008; Zhao and Fu 2006a). An important reason is that it is likely that climatic variables directly changing along with elevation have more explicit physical meaning, and are much easier to make sense of. The explicit physical meaning largely suggests that methods and results are more robust. 


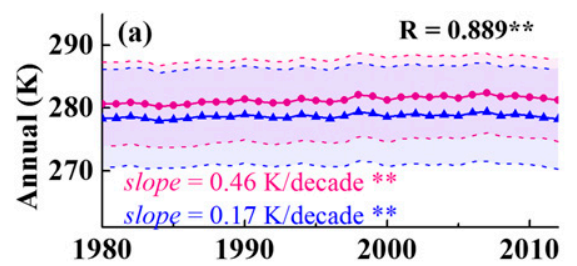

\section{Temperature}

$\rightarrow$ STA _- ERA-Interim
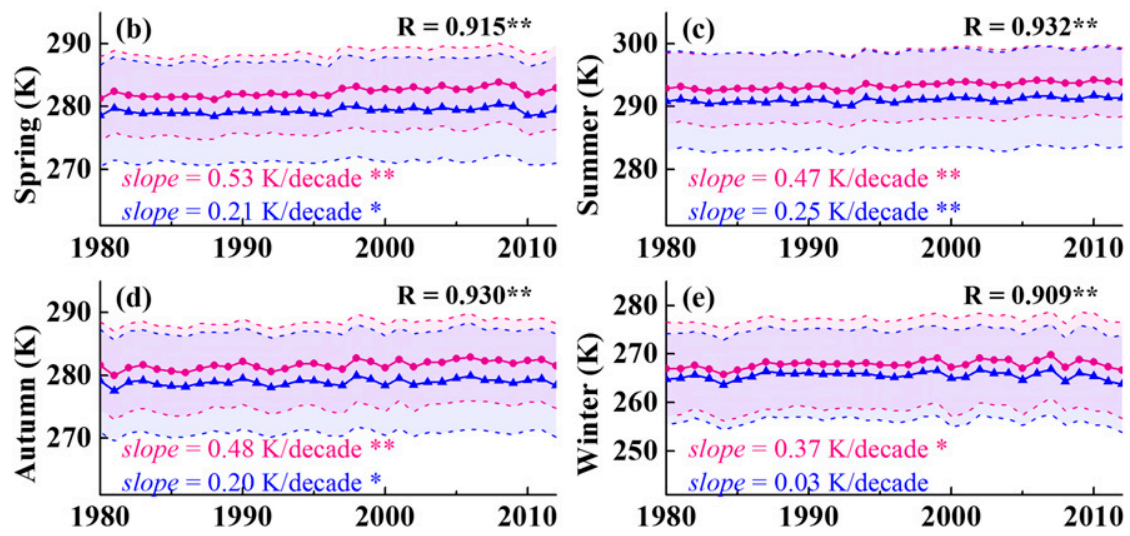

FIG. 9. As in Fig. 4, but for temperature.

Using STA data, this study examines the seasonal and annual spatial patterns and trends of ERA-Interim precipitation and temperature in China over the past three decades. As we knew, verification of reanalysis data is a very important issue. Previous studies generally used site-to-site means to validate the performances of reanalysis data (Bao and Zhang 2013; Mooney et al. 2011; Szczypta et al. 2011), while in this study we employed the interpolated data based on ground observations (STA data) to evaluate the ERA-Interim precipitation and temperature. Compared with previous studies (Ma et al. 2008, 2009; Wu and Gao 2013; Zhao and $\mathrm{Fu}$ 2006a,b; Zhou et al. 2016), our findings uncover that ERA-Interim precipitation and temperature show good agreement with STA data in east China with lower elevation $(<1000 \mathrm{~m}$ above sea level), but the good agreements are not observed in west China with higher elevation. Also, at annual and seasonal scales, ERA-Interim has larger precipitation amounts relative to STA precipitation, and interannual ERA-Interim temperature records have weaker warming trends compared to corresponding STA temperature. Certainly, although the strengths of interpolated data help us to better understand the reliability of reanalysis data and their feasibility in space, these interpolated data are bound to derive some errors in the areas with sparseobserved stations (Hutchinson et al. 2009). Many studies have found that most of the interpolation methods, including kriging, trend-surface regression, and inverse-distance weighting, often perform well over regions with lower elevation or relatively covered by dense stations (Yuan et al. 2015; Yue et al. 2016). Besides, unlike some previous studies in specific regions or seasons (Bao and Zhang 2013; Chen et al. 2014; You et al. 2015), this study provides a greater insight into the evaluation of the continuous temporal and

TABLE 3. The magnitudes of variability (using spatial STD) of temperature between ERA-Interim and STA data at seasonal and annual scales. The mean and slope are the average and trend of each climatic variable during 1980-2012. An asterisk indicates significance at the 0.05 level.

\begin{tabular}{|c|c|c|c|c|}
\hline & \multicolumn{4}{|c|}{ Temperature } \\
\hline & \multicolumn{2}{|c|}{ ERA-Interim spatial STD } & \multicolumn{2}{|c|}{ STA spatial STD } \\
\hline & Mean $(\mathrm{K})$ & Slope $\left(\mathrm{K} \mathrm{decade}^{-1}\right)$ & Mean (K) & Slope $\left(\mathrm{K} \mathrm{decade}^{-1}\right)$ \\
\hline Spring & 8.1 & 0.04 & 6.4 & -0.01 \\
\hline Summer & 7.8 & $0.05^{*}$ & 5.6 & -0.03 \\
\hline Autumn & 8.1 & 0.05 & 6.8 & $-0.08 *$ \\
\hline Winter & 9.3 & $0.12^{*}$ & 9.4 & 0.06 \\
\hline Annual & 7.8 & $0.04 *$ & 6.6 & $-0.06^{*}$ \\
\hline
\end{tabular}



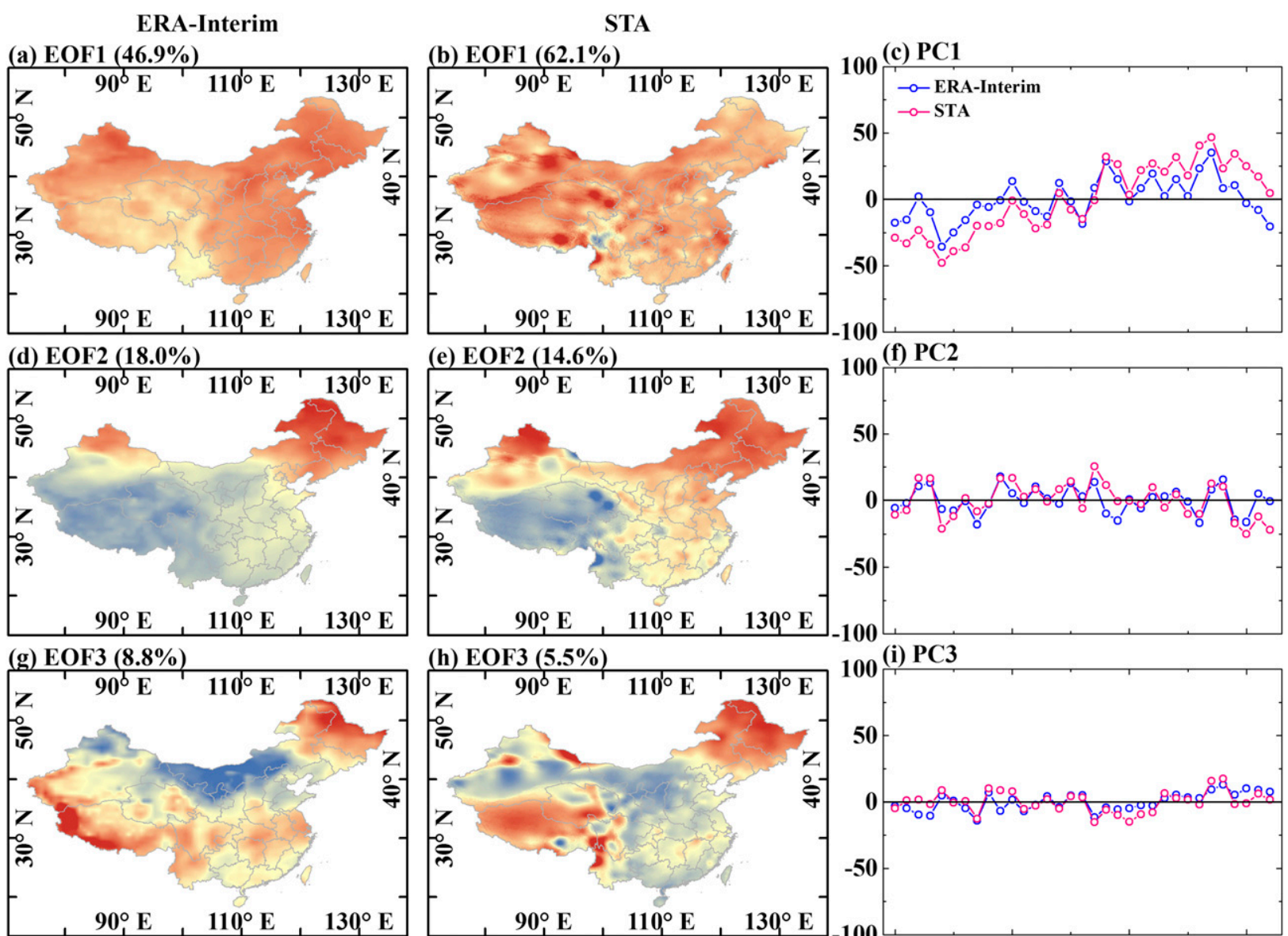

(h) EOF3 (5.5\%)
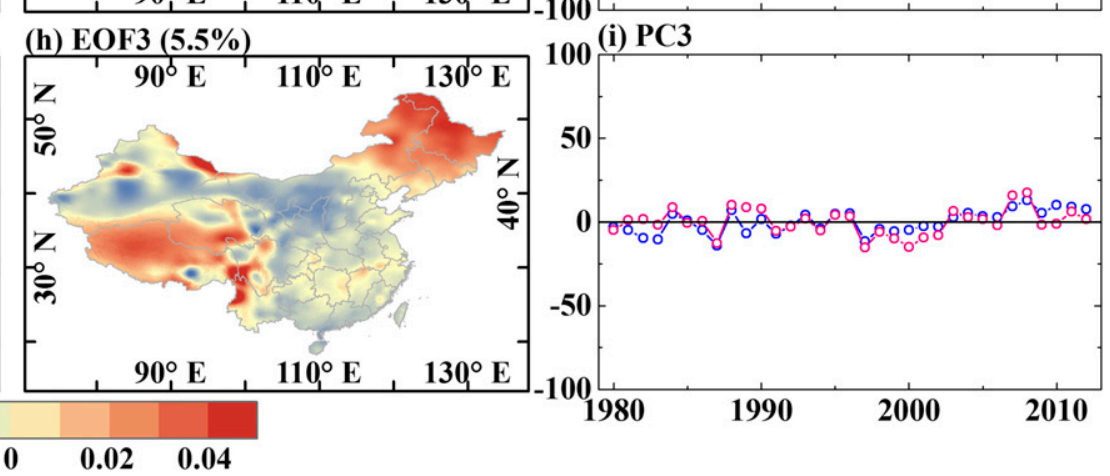

FIG. 10. As in Fig. 5, but for temperature.

spatial performances of ERA-Interim data in different ecoclimatic regions and seasons in China. For example, northwest China and southwest China both exhibited big differences in annual and seasonal climate variables and thus contributed more than the other three regions to the difference of entire China. The evaluations are very helpful for improving our understanding of the uncertainties of ERAInterim data in the different regions and seasons of China.

To reduce the error of interpolated data, this study uses 756 Chinese stations and 186 international stations together to enhance the interpolation accuracy. A recent study reported that mean absolute error of interpolated data was decreased by an average of $0.6^{\circ} \mathrm{C} \mathrm{yr}^{-1}$ when stations of neighboring countries were used in temperature interpolation (Ma et al. 2015). Therefore, the use of stations of neighboring countries could potentially improve the accuracy of our interpolated data. Yuan et al. (2015) used 600 Chinese stations and the thin-plate spline interpolation method to generate daily gridded precipitation and temperature datasets, and used 150 independent stations to validate the performance of interpolated data. They reported that large uncertainties were observed over northwest China and southwest China (the Tibetan Plateau) because of inadequacies in observed networks and complex orography. Similar issues could also inevitably exist in our study. Overall, more caution should be taken, especially in regions with higher elevation or sparseobserved stations, such as some regions of northwest China and southwest China.

The relationship between STA annual temperature trends and the elevation was investigated in mainland China (Fig. 12). A significant positive correlation was found between the elevation and annual temperature trends over the past 33 years. The warming rate of annual temperature increase with height was $0.06 \mathrm{~K}_{\text {decade }}{ }^{-1} \mathrm{~km}^{-1}(p<0.01)$. Below $3300 \mathrm{~m}$ above mean sea level (MSL), the warming rate of annual temperature increase with height was $0.07 \mathrm{~K} \mathrm{decade}^{-1} \mathrm{~km}^{-1}$ $(p<0.01)$. However, the warming rate decrease with height 
(a) Annual

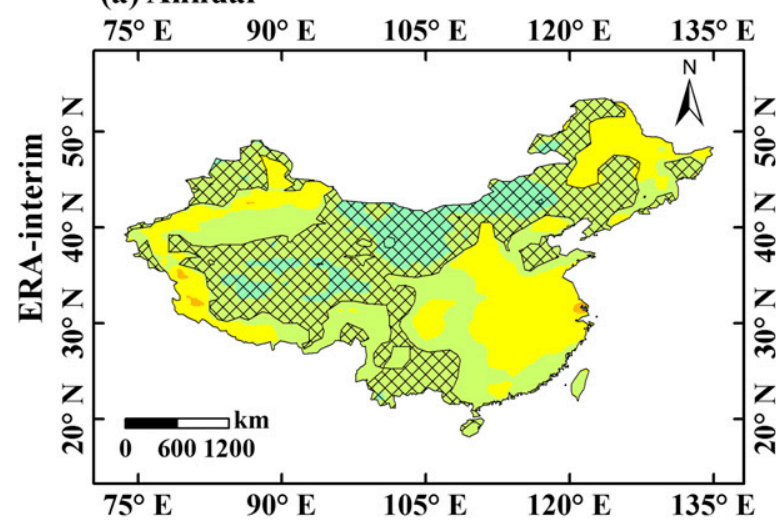

(f) Annual

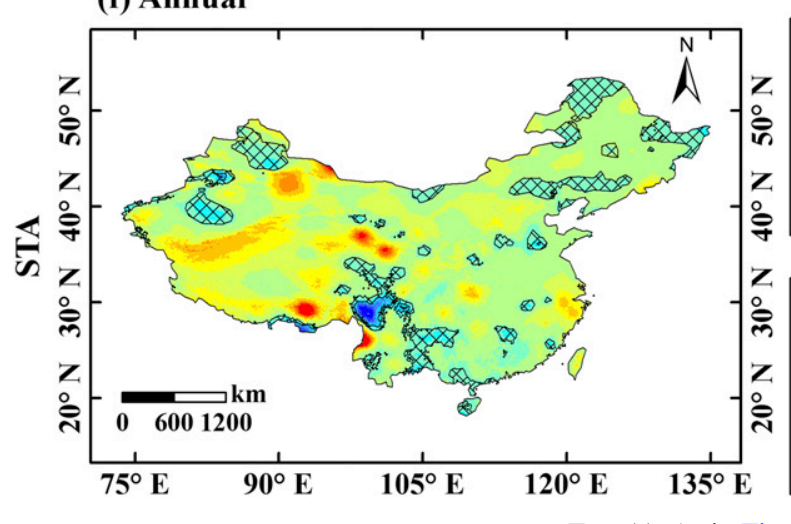

(b) Spring

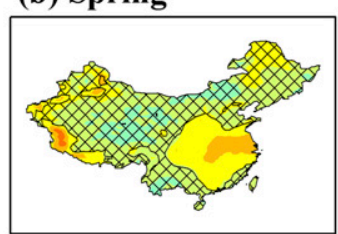

(d) Autumn

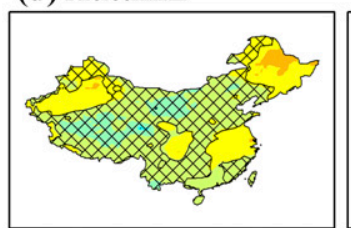

(g) Spring

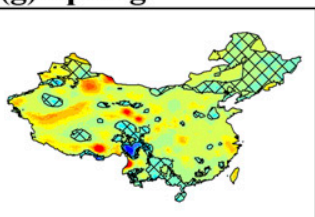

(i) Autumn

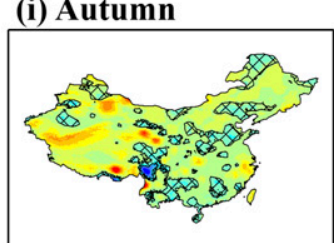

(c) Summer

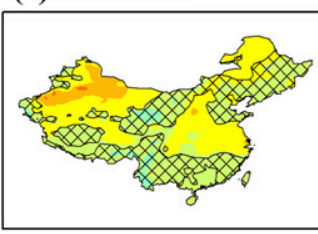

(e) Winter

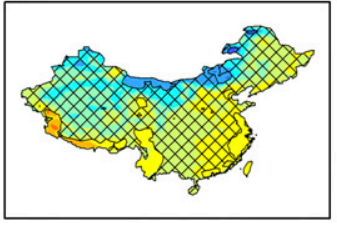

(h) Summer

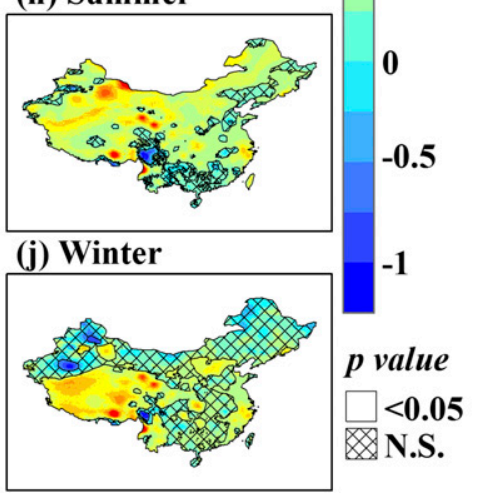

Trend (K/decade) 2

1.5

1

0.5

FIG. 11. As in Fig. 6, but for temperature.

(slope $=-0.13 \mathrm{~K} \mathrm{decade}^{-1} \mathrm{~km}^{-1} ; p<0.01$ ) was found in the elevation of $3300-4300 \mathrm{~m}$ MSL. Ecological restoration in these regions increased the vegetation cover and then altered the land surface biophysical properties, which could be responsible for the slowdown of the warming rate (Fan et al. 2010; Shao et al. 2017; Tao et al. 2014; Tudoroiu et al. 2016). Particularly, an amplified warming rate was observed above $4300 \mathrm{~m}$ MSL. It is possible that less snow and ice cover in high mountains results in relative lower surface albedo and then enhances further warming (Pepin and Losleben 2002; Pepin and Lundquist 2008). Some studies also reported that the amplification of global warming in high mountains was more sensitive (Beniston and Rebetez 1996; Liu and Chen 2000).

ERA-Interim precipitation and temperature are in good agreements with those of STA in eastern China where elevation is generally lower than $1000 \mathrm{~m}$ MSL, as bias is closer to $0 \%$ and $\mathrm{S}$ index is generally greater than 0.5 for precipitation and 0.7 for temperature in our results (Fig. 13). However, large differences are observed in mountainous regions, especially in the Tibetan Plateau, with an average elevation above $4000 \mathrm{~m}$ MSL. These findings are consistent with recent studies that comprehensively evaluate the performances of some reanalysis datasets in the Tibetan Plateau (Fan et al. 2013; Feng and Zhou 2012; Gao and Hao 2014; Gevorgyan 2013; Hu et al. 2013; Li et al. 2012; You et al. 2015). For example, a similar phenomenon is also found in ERA-Interim predecessor ERA-40 (You et al. 2013; Zhao and Fu 2006b; Zhao et al. 2008; Zolina et al. 2004).

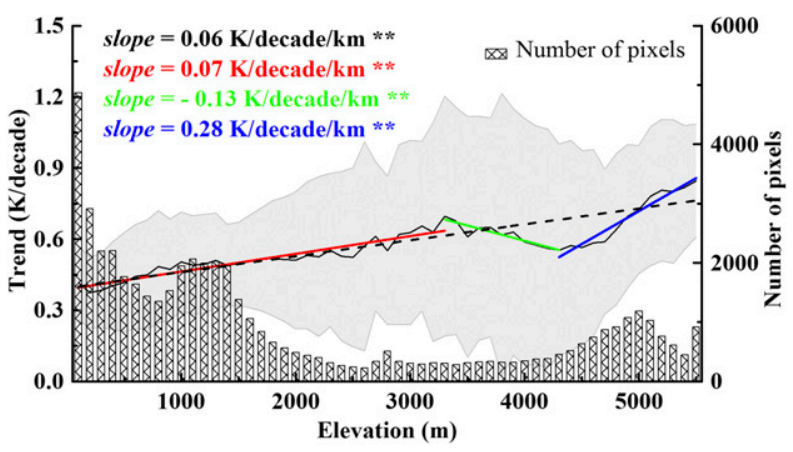

FIG. 12. STA annual temperature changes and their corresponding STD (the gray region) over elevation in mainland China. The changes with the statistical significance $(p<0.05)$ and corresponding number of pixels in each $100-\mathrm{m}$ bin were only counted. The double asterisks indicate significance at the 0.01 statistical level. 
(a)

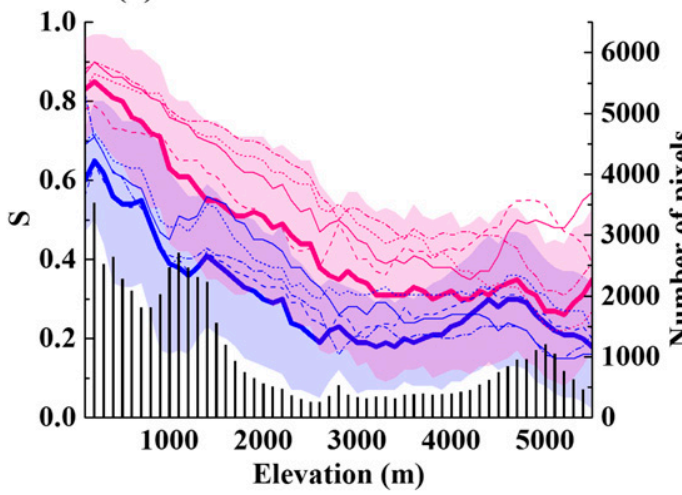

(b)

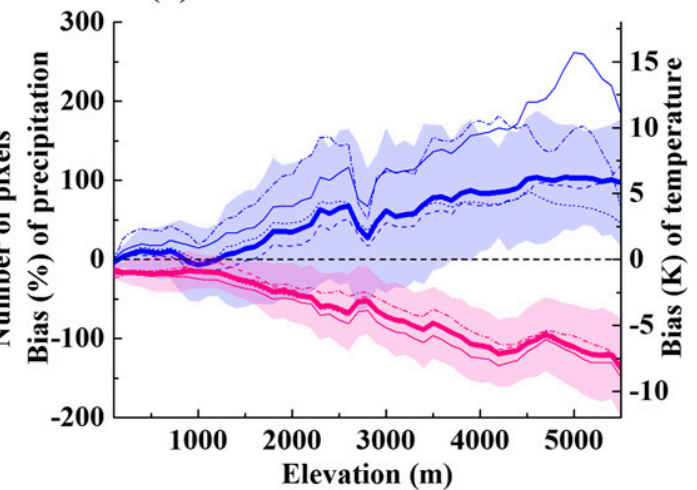

—Annual precipitation - Annual temperature

— Spring …... Summer …. Autumn …... Winter

FIG. 13. Variations of S index and (a) number of pixels and (b) bias of precipitation and temperature with elevation. The thick solid lines represent variations of annual climatic variables, and light solid lines represent variations of seasonal climatic variables. The shaded areas represent the variability of annual precipitation (blue) and temperature (pink).

Using the data of the meteorological stations, Zhao et al. (2008) investigated the relationship between topographic correction and reanalysis surface temperature errors (NCEP-1 and ERA-40), and showed that the bias was usually in proportion to the increase of local elevation and topographical complexity. Gao and Hao (2014) analyzed the difference between ERA-Interim elevation and site elevation, investigated the relationship between elevation difference and temperature bias, and indicated that elevation difference could affect the accuracy of reanalysis data, especially in regions with higher elevation (the difference being generally more than 0.5 or $1 \mathrm{~km}$ ). They therefore suggested that an elevation correction for ERA-Interim temperature was necessary before regional applications (Gao et al. 2017). ERA-Interim data is based on USGS GTOPO30 data (Dee et al. 2011). Particularly, the accuracy of GTOPO30 data largely depends on the accuracy of source data in each region, since GTOPO30 data are a product of multisource data fusion, and their accuracy is not uniformly consistent around the globe (Cowan and Cooper 2005). Thus, the elevation-induced bias could be responsible for the uncertainties of reanalysis data (Gao et al. 2017; Zhao et al. 2008). On the other hand, the ECMWF website offers a default spatial resolution grid of $0.75^{\circ}$ and also offers a scheme of variable spatial resolutions (ranging from a $0.125^{\circ}$ to $3^{\circ}$ grid) based on a bilinear interpolation technique without considering DEM. This may induce a great uncertainty in complex orography (Hutchinson et al. 2009; Liu et al. 2012; Price et al. 2000). Recent studies have mentioned that the use of limited-area models nested within global or regional climatic models or different statistical downscaling methods might provide the ability to resolve problems of complex orography (Gevorgyan 2013). Thus, a potential solution is to put a more accurate DEM into climatic models or assimilation systems. The SRTM DEM is a state-of-the-art DEM product so far, which provides a homogeneous near-global DEM of Earth from $60^{\circ} \mathrm{N}$ to $56^{\circ} \mathrm{S}$, covering $\sim 80 \%$ of Earth's landmass (Cowan and Cooper 2005). The SRTM data are also used to update the older USGS GTOPO30 global DEM and replaces the wild guesswork of previous data with actual measured values (Cowan and Cooper 2005). There are studies reporting that estimations based on SRTM data show lower standard errors and higher coefficients of determination than those obtained from GTOPO30-based (Lyra et al. 2011) data. Theoretically, a more accurate DEM is helpful for decreasing the bias of estimations (Lyra et al. 2011; Zhao et al. 2008), but further research is needed to address the impact of different DEMs (e.g., SRTM and GTOPO30) on estimated climatic variables at the coarser spatial resolution.

To obtain meaningful climatic variables, observed surface pressure, 2-m air temperature, 2-m relative humidity, and 10-m winds from stations were assimilated in the reanalysis system (Dee et al. 2011). Certainly, these observations assimilated in ERA-Interim are responsible for the improvement of data quality. However, we must note that data assimilation can fill the gaps by adding physically meaningful information from forecast models, but not without uncertainty (Dee et al. 2011). The uncertainty, including errors of numerical simulation, assimilation scheme, and observation system, can potentially affect the abilities of ERA-Interim data in capturing real climate features. Some studies thus indicate that to some extent, to reflect the true state of the atmosphere, it is hard to completely replace observations with reanalysis data 
(Bengtsson et al. 2004; Li et al. 2012). For example, Bengtsson et al. (2004) reported that ERA-40 data were not suitable for long-term climate trend calculations. In this study, we also find that interannual changes of annual and seasonal ERA-Interim data do not correspond to those of STA data.

By contrast, ERA-Interim temperature has a better consistency with STA data than ERA-Interim precipitation. Two reasons may be responsible for this phenomenon. First, accurate estimation of the hydrological cycle in reanalysis presents a special challenge since it involves many driving parameters in climatic models that are constrained only indirectly by observations (AgustíPanareda et al. 2010; Dee et al. 2011; Di Giuseppe et al. 2013). Second, unlike ERA-Interim temperature products, observed precipitation (e.g., gauge-based precipitation or satellite-based precipitation) has not been assimilated into the initial precipitation field (Dee et al. 2011). Commonly, estimation of ERA-Interim precipitation is derived from the forecast model, based on temperature and humidity information produced from the assimilated observations (Blenkinsop et al. 2015; Dee et al. 2011). Thus, errors of temperature and humidity could transfer into predicted precipitation via forecast model, and result in greater error.

\section{Conclusions}

Based on the STA data during 1980-2012, we verified that ERA-Interim precipitation and temperature showed better consistencies with STA data in eastern China with lower elevation ( $\mathrm{S}$ index $>0.5$ for precipitation and $\mathrm{S}$ index $>0.8$ for temperature) than in western China with higher elevation ( $\mathrm{S}$ index $<0.4$ for precipitation and $\mathrm{S}$ index $<0.6$ for temperature). At the regional and seasonal scales, ERA-Interim temperature showed a stronger agreement with STA temperature, but the similar agreement was weakened in ERA-Interim precipitation with STA precipitation. Besides, spatial patterns of EOF modes and corresponding principal components were evidently different between annual ERA-Interim and STA precipitation. The study suggests that we should consider the uncertainty of ERA-Interim precipitation and temperature in higher-elevation regions when using these data in specific studies.

Acknowledgments. We thank ECMWF for providing ERA-Interim data and the China Meteorological Administration (CMA) for providing meteorological observations. We appreciate Drs. Jia Wu, Lu Gao, Qiang Yu, Xuezhen Zhang, Kaicun Wang, Ruiqing Li, Hanqing Ma, Jianwu Yan, and three anonymous reviewers and editors for their valuable suggestions and comments, which significantly improved this manuscript. This study is funded by the National Key Research and Development Program of China (Grant 2017YFC0504701) and the National Natural Science Foundation of China (Grant 41601582).

\section{APPENDIX}

\section{Evaluation Metrics}

The average difference between ERA-Interim variable and STA variable (bias) and the skill score $[S$ or S index, being used to quantify the similarity of the distribution and amplitude of the spatial patterns between ERA-Interim variable and STA variable (Hirota et al. 2011; Taylor 2001)] were computed using the following equations:

$$
\begin{gathered}
\operatorname{Bias}=a \frac{1}{n} \sum_{i=1}^{n}\left(X_{\mathrm{ERA}_{-} i}-X_{\mathrm{STA}_{-} i}\right), \\
S=\frac{(1+R)^{4}}{4\left(\mathrm{SDR}+\frac{1}{\mathrm{SDR}}\right)^{2}},
\end{gathered}
$$

where $X_{\text {ERA } \_i}$ represents the $i$ th year ERA-Interim climatic variable; $X_{\mathrm{STA}_{-} i}$ is the $i$ th year STA climatic variable; and $\overline{X_{\mathrm{ERA}}}$ and $\overline{X_{\mathrm{STA}}}$ represent the average of multiyear $X_{\mathrm{ERA} \_i}$ and $X_{\mathrm{STA} \_i}$, respectively, particularly when $X$ is precipitation, $a=100 \% / \overline{X_{\mathrm{STA}}}$. At this point, bias 
presents the relative differences between ERA-Interim precipitation and STA precipitation. When $X$ represents temperature, the absolute differences in bias and RMSE appear to be more meaningful in view of temperature being measured at an interval scale. Thus, $a=1$. In the S-index equation, $R$ is the correlation coefficient between the ERAInterim variable and STA variable, and SDR is the ratio of the STD of the ERA-Interim variable against that of the STA variable at the spatial scale. The term $X_{i}$ represents the $i$ th year ERA-Interim or STA climatic variable, and $\bar{X}$ represents the average of multiyear $X_{i}$. Additionally, $X$ should be converted to kelvin so as to spatially analyze the differences. The analysis of variance (ANOVA) technique was used to investigate the significance of spatial differences between ERA-Interim and STA data. The absolute differences between ERA-Interim data and STA data were analyzed at regional and national scales, respectively. Besides, to more comprehensively reveal interannual variability of climatic variables of ERA-Interim data and STA data, we further analyzed correlations of interannual changes, magnitudes of spatial variabilities, and the spatiotemporal patterns of interannual variabilities. The $R$ value between time series was used to measure how well ERA-Interim data matched STA data on the interannual changes. The STD was employed to represent the magnitude of variabilities. The EOF analysis was used to reveal the temporal and spatial patterns of interannual variabilities (Björnsson and Venegas 1997). We used the sampling error method to select the leading eigenvectors (or modes) of EOF analysis and corresponding principal components (North et al. 1982). The sampling error of the eigenvalue $\Delta \lambda$ was defined as follows:

$$
\Delta \lambda_{i}=\lambda_{i} \sqrt{\frac{2}{N^{*}}},
$$

where $\lambda_{i}$ is the $i$ th eigenvalue, and $N^{*}$ is the number of degrees of freedom. If two neighboring eigenvalues meet Eq. (A6), it illustrates that the first $i+1$ leading modes are valuable signals with an explicit physical meaning. For easier comparison, ERA-Interim and STA are forced to have the same leading modes, which are decided by the minimum number of leading modes between ERA-Interim and STA:

$$
\lambda_{i}-\lambda_{i+1} \geq \Delta \lambda_{i}+\Delta \lambda_{i+1} .
$$

The least squares method was used to solve the trends (or slope values) of climatic variables at the spatial scales (Wang et al. 2017):

$$
\text { slope }=\frac{n \sum X_{i} Y_{i}-\sum X_{i} \sum Y_{i}}{n \sum X_{i}^{2}-\left(\sum X_{i}\right)^{2}},
$$

where $X_{i}$ is the climatic variable of the $i$ th year, $Y_{i}$ is the temperature or precipitation of the $i$ th year, and $n$ is the number of years. The statistical significance of the trends is computed from the $p$ value of the two-tailed Student's $t$ test. In this study, a significant or very significant difference is attained when the observed $p$ value is less than 0.05 or 0.01 (the significance level). Conversely, if the $p$ value is greater than 0.05 , the difference is regarded as having no statistical significance.

\section{REFERENCES}

Adler, R. F., and Coauthors, 2003: The version-2 Global Precipitation Climatology Project (GPCP) monthly precipitation analysis (1979-present). J. Hydrometeor., 4, 1147-1167, https://doi.org/ 10.1175/1525-7541(2003)004<1147:TVGPCP >2.0.CO;2.

Agustí-Panareda, A., G. Balsamo, and A. Beljaars, 2010: Impact of improved soil moisture on the ECMWF precipitation forecast in West Africa. Geophys. Res. Lett., 37, L20808, https://doi.org/ 10.1029/2010GL044748.

Bao, X., and F. Zhang, 2013: Evaluation of NCEP-CFSR, NCEPNCAR, ERA-Interim, and ERA-40 reanalysis datasets against independent sounding observations over the Tibetan Plateau. J. Climate, 26, 206-214, https://doi.org/10.1175/JCLI-D-12-00056.1.

Bengtsson, L., S. Hagemann, and K. I. Hodges, 2004: Can climate trends be calculated from reanalysis data? J. Geophys. Res., 109, D11111, https://doi.org/10.1029/2004JD004536.

Beniston, M., and M. Rebetez, 1996: Regional behavior of minimum temperatures in Switzerland for the period 1979-1993. Theor. Appl. Climatol., 53, 231-243, https://doi.org/10.1007/BF00871739.

Björnsson, H., and S. A. Venegas, 1997: A manual for EOF and SVD analyses of climatic data. CCGCR Rep. 97-1, 52 pp.

Blenkinsop, S., S. C. Chan, E. J. Kendon, N. M. Roberts, and H. J. Fowler, 2015: Temperature influences on intense UK hourly precipitation and dependency on large-scale circulation. Environ. Res. Lett., 10, 054021, https://doi.org/10.1088/1748-9326/10/5/054021.

Bosilovich, M. G., J. Chen, F. R. Robertson, and R. F. Adler, 2008: Evaluation of global precipitation in reanalyses. J. Appl. Meteor. Climatol., 47, 2279-2299, https://doi.org/10.1175/2008JAMC1921.1.

Buermann, W., B. R. Lintner, C. D. Koven, A. Angert, J. E. Pinzon, C. J. Tucker, and I. Y. Fung, 2007: The changing carbon cycle at Mauna Loa Observatory. Proc. Natl. Acad. Sci. USA, 104, 4249-4254, https://doi.org/10.1073/pnas.0611224104.

Cai, D., K. Fraedrich, F. Sielmann, Y. Guan, S. Guo, L. Zhang, and X. Zhu, 2014: Climate and vegetation: An ERA-Interim and GIMMS NDVI analysis. J. Climate, 27, 5111-5118, https://doi.org/ 10.1175/JCLI-D-13-00674.1.

- — - - L. Zhang, X. Zhu, S. Guo, and Y. Guan, 2015: Vegetation dynamics on the Tibetan Plateau (1982-2006): An attribution by ecohydrological diagnostics. J. Climate, 28, 4576-4584, https://doi.org/10.1175/JCLI-D-14-00692.1.

Cane, M. A., 2010: Climate science: Decadal predictions in demand. Nat. Geosci., 3, 231-232, https://doi.org/10.1038/ngeo823.

Chen, G., T. Iwasaki, H. Qin, and W. Sha, 2014: Evaluation of the warmseason diurnal variability over East Asia in recent reanalyses JRA55, ERA-Interim, NCEP CFSR, and NASA MERRA. J. Climate, 27, 5517-5537, https://doi.org/10.1175/JCLI-D-14-00005.1.

Colucci, R. R., and M. Guglielmin, 2015: Precipitation-temperature changes and evolution of a small glacier in the southeastern European Alps during the last 90 years. Int. J. Climatol., 35, 2783-2797, https://doi.org/10.1002/joc.4172.

Cowan, D., and G. Cooper, 2005: The Shuttle Radar Topography Mission: A new source of near-global digital elevation data. Explor. Geophys., 36, 334-340, https://doi.org/10.1071/EG05334. 
Decker, M., M. A. Brunke, Z. Wang, K. Sakaguchi, X. Zeng, and M. G. Bosilovich, 2012: Evaluation of the reanalysis products from GSFC, NCEP, and ECMWF using flux tower observations. J. Climate, 25, 1916-1944, https://doi.org/ 10.1175/JCLI-D-11-00004.1.

Dee, D. P., and S. Uppala, 2009: Variational bias correction of satellite radiance data in the ERA-Interim reanalysis. Quart. J. Roy. Meteor. Soc., 135, 1830-1841, https://doi.org/10.1002/qj.493.

— ration and performance of the data assimilation system. Quart. J. Roy. Meteor. Soc., 137, 553-597, https://doi.org/10.1002/qj.828.

de Leeuw, J., J. Methven, and M. Blackburn, 2015: Evaluation of ERA-Interim reanalysis precipitation products using England and Wales observations. Quart. J. Roy. Meteor. Soc., 141, 798806, https://doi.org/10.1002/qj.2395.

Diaconescu, E. P., P. Gachon, J. Scinocca, and R. Laprise, 2015: Evaluation of daily precipitation statistics and monsoon onset/ retreat over western Sahel in multiple data sets. Climate Dyn., 45, 1325-1354, https://doi.org/10.1007/s00382-014-2383-2.

, A. Mailhot, R. Brown, and D. Chaumont, 2018: Evaluation of CORDEX-Arctic daily precipitation and temperature-based climate indices over Canadian Arctic land areas. Climate Dyn., 50, 2061-2085, https://doi.org/10.1007/s00382-017-3736-4.

Di Giuseppe, F., F. Molteni, and E. Dutra, 2013: Real-time correction of ERA-Interim monthly rainfall. Geophys. Res. Lett., 40, 3750-3755, https://doi.org/10.1002/grl.50670.

Fan, B., G. Luo, C. Zhang, Z. Hu, C. Li, Y. Wang, and L. Bai, 2013: Evaluation of summer precipitation of CFSR, ERA-Interim and MERRA reanalyses in Xinjiang (in Chinese). Geogr. Res., 32, 1602-1612.

Fan, J.-W., and Coauthors, 2010: Assessment of effects of climate change and grazing activity on grassland yield in the Three Rivers Headwaters Region of Qinghai-Tibet Plateau, China. Environ. Monit. Assess., 170, 571-584, https://doi.org/10.1007/ s10661-009-1258-1.

Feng, L., and T. Zhou, 2012: Water vapor transport for summer precipitation over the Tibetan Plateau: Multidata set analysis. J. Geophys. Res., 117, D20114, https://doi.org/10.1029/ 2011JD017012.

Fu, Y., J. Xia, W. Yuan, B. Xu, X. Wu, Y. Chen, and H. Zhang, 2016: Assessment of multiple precipitation products over major river basins of China. Theor. Appl. Climatol., 123, 1122, https://doi.org/10.1007/s00704-014-1339-0.

Gao, L., and L. Hao, 2014: Verification of ERA-Interim reanalysis data over China (in Chinese). J. Subtrop. Resour. Environ., 9, 75-81.

- M. Bernhardt, and K. Schulz, 2012: Elevation correction of ERAInterim temperature data in complex terrain. Hydrol. Earth Syst. Sci., 16, 4661-4673, https://doi.org/10.5194/hess-16-4661-2012.

,,--- , and X. Chen, 2017: Elevation correction of ERAInterim temperature data in the Tibetan Plateau. Int. J. Climatol., 37, 3540-3552, https://doi.org/10.1002/joc.4935.

Gevorgyan, A., 2013: Verification of daily precipitation amount forecasts in Armenia by ERA-Interim model. Int. J. Climatol., 33, 2706-2712, https://doi.org/10.1002/joc.3621.

Hirota, N., Y. N. Takayabu, M. Watanabe, and M. Kimoto, 2011: Precipitation reproducibility over tropical oceans and its relationship to the double ITCZ problem in CMIP3 and MIROC5 climate models. J. Climate, 24, 4859-4873, https:// doi.org/10.1175/2011JCLI4156.1.

Hu, Z., Y. Ni, H. Shao, G. Yin, Y. Yan, and C. Jia, 2013: Applicability study of CFSR, ERA-Interim and MERRA precipitation estimates in central Asia (in Chinese). Arid Land Geogr., 36, 700-708.
Huang, D.-Q., J. Zhu, Y.-C. Zhang, Y. Huang, and X.-Y. Kuang, 2016: Assessment of summer monsoon precipitation derived from five reanalysis datasets over East Asia. Quart. J. Roy. Meteor. Soc., 142, 108-119, https://doi.org/10.1002/qj.2634.

Hutchinson, M. F., D. W. McKenney, K. Lawrence, J. H. Pedlar, R. F. Hopkinson, E. Milewska, and P. Papadopol, 2009: Development and testing of Canada-wide interpolated spatial models of daily minimum-maximum temperature and precipitation for 1961-2003. J. Appl. Meteor. Climatol., 48, 725741, https://doi.org/10.1175/2008JAMC1979.1.

Jiang, R., T. Y. Gan, J. Xie, N. Wang, and C.-C. Kuo, 2017: Historical and potential changes of precipitation and temperature of Alberta subjected to climate change impact: 1900-2100. Theor. Appl. Climatol., 127, 725-739, https://doi.org/10.1007/ s00704-015-1664-y.

Kalnay, E., and Coauthors, 1996: The NCEP/NCAR 40-Year Reanalysis Project. Bull. Amer. Meteor. Soc., 77, 437-471, https:// doi.org/10.1175/1520-0477(1996)077<0437:TNYRP>2.0.CO;2.

Kanamitsu, M., W. Ebisuzaki, J. Woollen, S.-K. Yang, J. J. Hnilo, M. Fiorino, and G. L. Potter, 2002: NCEP-DOE AMIP-II Reanalysis (R-2). Bull. Amer. Meteor. Soc., 83, 1631-1643, https://doi.org/10.1175/BAMS-83-11-1631.

Kobayashi, S., and Coauthors, 2015: The JRA-55 Reanalysis: General specifications and basic characteristics. J. Meteor. Soc. Japan, 93, 5-48, https://doi.org/10.2151/jmsj.2015-001.

Li, R., S. Lv, B. Han, and Y. Gao, 2012: Preliminary comparison and analyses of air temperature at $2 \mathrm{~m}$ height between three reanalysis data-sets and observation in the east of QinghaiXiang Plateau (in Chinese). Plateau Meteor., 31, 1488-1502.

Liu, X., and B. Chen, 2000: Climatic warming in the Tibetan Plateau during recent decades. Int. J. Climatol., 20, 1729_ 1742, https://doi.org/10.1002/1097-0088(20001130)20:14<1729:: AID-JOC556>3.0.CO;2-Y.

Liu, Y., D. Wang, J. Gao, and W. Deng, 2005: Land use/cover changes, the environment and water resources in northeast China. Environ. Manage., 36, 691-701, https://doi.org/10.1007/ s00267-004-0285-5.

_ Y. Yuo, Y. Li, and Y. Li, 2015: GIS-based effect assessment of soil erosion before and after gully land consolidation: A case study of Wangiiagou project region, Loess Plateau. Chin. Geogr. Sci., 25, 137-146, https://doi.org/10.1007/s11769-015-0742-5.

Liu, Z., X. Yu, S. Wang, and G. Shang, 2012: Comparative analysis of three covariates methods in thin-plate smoothing splines for interpolating precipitation (in Chinese). Prog. Geogr., 31, 56-62.

Lyra, G. B., M. J. dos Santos, J. L. De Souza, and M. A. dos Santos, 2011: Mapping annual air temperature in Alagoas state, Brazil, with different digital elevation models and spatial resolutions. Ciênc. Florest., 21, 275-287.

Ma, J., W. Dong, Z. Wei, and X. Yan, 2015: Evaluating daily surface maximum temperature interpolation error by adding climate stations near border areas over China. Int. J. Climatol., 35, 2798-2808, https://doi.org/10.1002/joc.4173.

Ma, L., T. Zhang, Q. Li, O. W. Frauenfeld, and D. Qin, 2008: Evaluation of ERA-40, NCEP-1, and NCEP-2 reanalysis air temperatures with ground-based measurements in China. J. Geophys. Res., 113, D15115, https://doi.org/10.1029/2007JD009549.

, O. W. Frauenfeld, B. Ye, D. Yang, and D. Qin, 2009: Evaluation of precipitation from the ERA-40, NCEP-1, and NCEP-2 reanalyses and CMAP-1, CMAP-2, and GPCP-2 with ground-based measurements in China. J. Geophys. Res., 114, D09105, https://doi.org/10.1029/2008JD011178.

Madonna, E., H. Wernli, H. Joos, and O. Martius, 2014: Warm conveyor belts in the ERA-Interim dataset (1979-2010). Part 
I: Climatology and potential vorticity evolution. J. Climate, 27, 3-26, https://doi.org/10.1175/JCLI-D-12-00720.1.

Mooney, P. A., F. J. Mulligan, and R. Fealy, 2011: Comparison of ERA-40, ERA-Interim and NCEP/NCAR reanalysis data with observed surface air temperatures over Ireland. Int. J. Climatol, 31, 545-557, https://doi.org/10.1002/joc.2098.

National Meteorological Information Center, 2013: Dataset of daily climate data from Chinese surface stations, version 3.0. China Meteorological Data Service Center, accessed 1 October 2013, http://data.cma.cn/.

North, G. R., T. L. Bell, R. F. Cahalan, and F. J. Moeng, 1982: Sampling errors in the estimation of empirical orthogonal functions. Mon. Wea. Rev., 110, 699-706, https://doi.org/ 10.1175/1520-0493(1982)110<0699:SEITEO > 2.0.CO;2.

Oberhänsli, H., K. Novotná, A. Pîśková, S. Chabrillat, D. K. Nourgaliev, A. K. Kurbaniyazov, and T. Matys Grygar, 2011: Variability in precipitation, temperature and river runoff in w central Asia during the past $\sim 2000$ yrs. Global Planet. Change, 76, 95-104, https:// doi.org/10.1016/j.gloplacha.2010.12.008.

Onogi, K., and Coauthors, 2005: JRA-25: Japanese 25-year reanalysis project-Progress and status. Quart. J. Roy. Meteor. Soc., 131, 3259-3268, https://doi.org/10.1256/qj.05.88.

Pepin, N., and M. Losleben, 2002: Climate change in the Colorado Rocky Mountains: Free air versus surface temperature trends. Int. J. Climatol., 22, 311-329, https://doi.org/10.1002/joc.740.

- and J. Lundquist, 2008: Temperature trends at high elevations: Patterns across the globe. Geophys. Res. Lett., 35, L14701, https://doi.org/10.1029/2008GL034026.

Price, D. T., D. W. McKenney, I. A. Nalder, M. F. Hutchinson, and J. L. Kesteven, 2000: A comparison of two statistical methods for spatial interpolation of Canadian monthly mean climate data. Agric. For. Meteor., 101, 81-94, https://doi.org/10.1016/ S0168-1923(99)00169-0.

Sevruk, B., M. Ondrás, and B. Chvíla, 2009: The WMO precipitation measurement intercomparisons. Atmos. Res., 92 376-380, https://doi.org/10.1016/j.atmosres.2009.01.016.

Shao, Q., W. Cao, J. Fan, L. Huang, and X. Xu, 2017: Effects of an ecological conservation and restoration project in the ThreeRiver Source Region, China. J. Geogr. Sci., 27, 183-204, https://doi.org/10.1007/s11442-017-1371-y.

Song, F., and T. Zhou, 2012: Reliability of the 20CR reanalysis data in measuring the East Asian summer monsoon variability (in Chinese). Chin. J. Atmos. Sci., 36, 1207-1222.

Sylla, M. B., E. Coppola, L. Mariotti, F. Giorgi, P. M. Ruti, A. Dell'Aquila, and X. Bi, 2010: Multiyear simulation of the African climate using a regional climate model (RegCM3) with the high resolution ERA-Interim reanalysis. Climate Dyn., 35, 231-247, https://doi.org/10.1007/s00382-009-0613-9.

Szczypta, C., J.-C. Calvet, C. Albergel, G. Balsamo, S. Boussetta, D. Carrer, S. Lafont, and C. Meurey, 2011: Verification of the new ECMWF ERA-Interim reanalysis over France. Hydrol. Earth Syst. Sci., 15, 647-666, https://doi.org/10.5194/hess-15-647-2011.

Tao, J., Y. Zhang, J. Zhu, Y. Jiang, X. Zhang, T. Zhang, and Y. Xi, 2014: Elevation-dependent temperature change in the QinghaiXizang Plateau grassland during the past decade. Theor. Appl. Climatol., 117, 61-71, https://doi.org/10.1007/s00704-013-0976-z.

Tapiador, F. J., and Coauthors, 2012: Global precipitation measurement: Methods, datasets and applications. Atmos. Res., 104-105, 70-97, https://doi.org/10.1016/j.atmosres.2011.10.021.

Taylor, K. E., 2001: Summarizing multiple aspects of model performance in a single diagram. J. Geophys. Res., 106, 7183-7192, https://doi.org/10.1029/2000JD900719.
Tudoroiu, M., E. Eccel, B. Gioli, D. Gianelle, H. Schume, L. Genesio, and F. Miglietta, 2016: Negative elevationdependent warming trend in the eastern Alps. Environ. Res. Lett., 11, 044021, https://doi.org/10.1088/1748-9326/11/4/044021.

Uppala, S. M., and Coauthors, 2005: The ERA-40 Re-Analysis. Quart. J. Roy. Meteor. Soc., 131, 2961-3012, https://doi.org/ 10.1256/qj.04.176.

Vergni, L., and F. Todisco, 2011: Spatio-temporal variability of precipitation, temperature and agricultural drought indices in central Italy. Agric. For. Meteor., 151, 301-313, https://doi.org/ 10.1016/j.agrformet.2010.11.005.

Wang, S., X. Mo, Z. Liu, M. H. A. Baig, and W. Chi, 2017: Understanding long-term (1982-2013) patterns and trends in winter wheat spring green-up date over the north China plain. Int. J. Appl. Earth Obs. Geoinf., 57, 235-244, https://doi.org/ 10.1016/j.jag.2017.01.008.

Wernli, H., and M. Sprenger, 2007: Identification and ERA-15 climatology of potential vorticity streamers and cutoffs near the extratropical tropopause. J. Atmos. Sci., 64, 1569-1586, https://doi.org/10.1175/JAS3912.1.

$\mathrm{Wu}$, J., and X. Gao, 2013: A gridded daily observation dataset over China region and comparison with the other datasets (in Chinese). Chin. J. Geophys., 56, 1102-1111.

You, Q., K. Fraedrich, G. Ren, N. Pepin, and S. Kang, 2013: Variability of temperature in the Tibetan Plateau based on homogenized surface stations and reanalysis data. Int. J. Climatol., 33, 1337-1347, https://doi.org/10.1002/joc.3512.

- J. Min, W. Zhang, N. Pepin, and S. Kang, 2015: Comparison of multiple datasets with gridded precipitation observations over the Tibetan Plateau. Climate Dyn., 45, 791-806, https:// doi.org/10.1007/s00382-014-2310-6.

Yuan, W., B. Xu, Z. Chen, J. Xia, W. Xu, Y. Chen, X. Wu, and Y. Fu, 2015: Validation of China-wide interpolated daily climate variables from 1960 to 2011. Theor. Appl. Climatol., 119, 689-700, https://doi.org/10.1007/s00704-014-1140-0.

Yue, T., and Coauthors, 2016: CMIP5 downscaling and its uncertainty in China. Global Planet. Change, 146, 30-37, https:// doi.org/10.1016/j.gloplacha.2016.09.003.

Zhang, L., F. Sielmann, K. Fraedrich, X. Zhu, and X. Zhi, 2015: Variability of winter extreme precipitation in southeast China: Contributions of SST anomalies. Climate Dyn., 45, 2557-2570, https://doi.org/10.1007/s00382-015-2492-6.

Zhang, Q., H. Körnich, and K. Holmgren, 2013: How well do reanalyses represent the southern African precipitation? Climate Dyn., 40, 951-962, https://doi.org/10.1007/s00382-012-1423-z.

Zhao, T., and C. Fu, 2006a: Comparison of products from ERA-40, NCEP-2, and CRU with station data for summer precipitation over China. Adv. Atmos. Sci., 23, 593-604, https://doi.org/ 10.1007/s00376-006-0593-1.

$\longrightarrow$, and $-2006 \mathrm{~b}$ : Preliminary comparison and analysis between ERA-40, NCEP-2 reanalysis and observations over China (in Chinese). Climatic Environ. Res., 11, 14-32.

_ W. Wuo, and C. Fu, 2008: Calibrating and evaluating reanalysis surface temperature error by topographic correction. J. Climate, 21, 1440-1446, https://doi.org/10.1175/2007JCLI1463.1.

Zhou, B., Y. Xu, J. Wu, S. Dong, and Y. Shi, 2016: Changes in temperature and precipitation extreme indices over China: Analysis of a high-resolution grid dataset. Int. J. Climatol., 36, 1051-1066, https://doi.org/10.1002/joc. 4400.

Zolina, O., A. Kapala, C. Simmer, and S. K. Gulev, 2004: Analysis of extreme precipitation over Europe from different reanalyses: A comparative assessment. Global Planet. Change, 44, 129-161, https://doi.org/10.1016/j.gloplacha.2004.06.009. 